\title{
AirClim: an efficient tool for climate evaluation of aircraft technology
}

\author{
V. Grewe and A. Stenke \\ Deutsches Zentrum für Luft- und Raumfahrt, Institut für Physik der Atmosphäre, Oberpfaffenhofen, \\ 82230 Wessling, Germany
}

Received: 9 August 2007 - Published in Atmos. Chem. Phys. Discuss.: 17 August 2007

Revised: 4 March 2008 - Accepted: 27 May 2008 - Published: 11 August 2008

\begin{abstract}
Climate change is a challenge to society and to cope with requires assessment tools which are suitable to evaluate new technology options with respect to their impact on global climate. Here we present AirClim, a model which comprises a linearisation of atmospheric processes from the emission to radiative forcing, resulting in an estimate in near surface temperature change, which is presumed to be a reasonable indicator for climate change. The model is designed to be applicable to aircraft technology, i.e. the climate agents $\mathrm{CO}_{2}, \mathrm{H}_{2} \mathrm{O}, \mathrm{CH}_{4}$ and $\mathrm{O}_{3}$ (latter two resulting from $\mathrm{NO}_{\mathrm{x}}$-emissions) and contrails are taken into account. AirClim combines a number of precalculated atmospheric data with aircraft emission data to obtain the temporal evolution of atmospheric concentration changes, radiative forcing and temperature changes. These precalculated data are derived from 25 steady-state simulations for the year 2050 with the climate-chemistry model E39/C, prescribing normalised emissions of nitrogen oxides and water vapour at various atmospheric regions. The results show that strongest climate impacts (year 2100) from ozone changes occur for emissions in the tropical upper troposphere $\left(60 \mathrm{~mW} / \mathrm{m}^{2} ; 80 \mathrm{mK}\right.$ for $1 \mathrm{TgN} /$ year emitted) and from methane changes from emissions in the middle tropical troposphere $(-2.7 \%$ change in methane lifetime; $-30 \mathrm{mK}$ per TgN/year). For shortlived species (e.g. ozone, water vapour, methane) individual perturbation lifetimes are derived depending on the region of emission. A comparison of this linearisation approach with results from a comprehensive climate-chemistry model shows reasonable agreement with respect to concentration changes, radiative forcing, and temperature changes. For example, the total impact of a supersonic fleet on radiative forcing (mainly water vapour) is reproduced within $10 \%$. A wide range of application is demonstrated.
\end{abstract}

Correspondence to: V. Grewe (volker.grewe@dlr.de)

\section{Introduction}

Air traffic has the potential to grow over-proportional compared to other transport sectors. Its specific climate impact, i.e. relative to fuel consumption is larger than for other sectors (Fuglestvedt et al., 2008). The higher altitude of the emission leads to longer atmospheric residence times, particularly in the case of $\mathrm{NO}_{\mathrm{x}}$ emissions and its chemical products (ozone, methane). Furthermore, the formation of contrails adds to the warming effect of air traffic.

Therefore, there is a need to develop technical and operational options to reduce the impact from air traffic emissions on climate. And there is a need for tools, such as AirClim, for evaluating the climate impact of such options.

In this context it is important to note that a simple metric based on fuel consumption or emission indices insufficiently describes the total climate impact. The dependency of climate impact on altitude and region of air traffic emissions cannot be described by such metrics. For example, contrail formation depends on aircraft design aspects (propulsion efficiency), water vapour emission (directly related to fuel consumption), but also and equally important on local atmospheric conditions (Schumann et al., 2000).

We concentrate on near surface temperature changes as a metric for climate change, as we think it is the most suitable metric for our purpose. However, we also include radiative forcing considerations to be comparable to other publications. Generally, those metrics provide an accumulated impact of historical emissions, especially for $\mathrm{CO}_{2}$. Since we want to focus on the climate impact of future technology options, we look at differences in near surface temperature changes between an background aircraft scenario plus the new technology and this background aircraft scenario. This removes the historical impacts and assesses the future emissions of that new technology, only. Hence both, radiative forcing and near surface temperature changes, become a forward looking metric. Other metrics, e.g. global warming

Published by Copernicus Publications on behalf of the European Geosciences Union. 
Table 1. Pressure levels $\left(\mathrm{P}_{\mathrm{id}}\right)$ in $[\mathrm{hPa}]$ of idealised emission scenarios.

\begin{tabular}{lll}
\hline $\mathrm{P}_{\text {id }}$ & Description & Abbreviation \\
\hline 52 & Supersonic Cruise Level - High & SSCL-H \\
89 & Supersonic Cruise Level - Medium & SSCL-M \\
132 & Supersonic Cruise Level - Low & SSCL-L \\
198 & Subsonic Cruise Level & SubCL \\
499 & Climb High & Climb-H \\
967 & Climb Low & Climb-L \\
\hline
\end{tabular}

potentials or time-integrated radiative forcing, weighted with its efficacy have been widely discussed (Fuglestvedt et al., 2003; Shine et al., 2005a,b; Wit et al., 2005; Forster et al., 2006, 2007). Generally it can be summarized from those papers that an optimal metric has yet not been designed. However, some, e.g. global warming potential and radiative forcing index, are less appropriate than others. Forster et al. $(2006,2007)$ gave a list of requirements for a climate metric, which we are addressing in more detail in the conclusions.

Here we present an assessment tool, AirClim, which is an extension to the linear response model described in Sausen and Schumann (2000). The extension comprises a linearisation of the relation between emissions of $\mathrm{CO}_{2}, \mathrm{NO}_{\mathrm{x}}$ and $\mathrm{H}_{2} \mathrm{O}$ and impacts on atmospheric composition related to carbon dioxide, ozone, methane, water vapour, and contrails. Note that in our approach spatially resolved emissions are taken into account in contrast to Sausen and Schumann (2000) who concentrated on annual global values. Hence, the input to the AirClim model are 3-D aircraft emission data, precalculated atmospheric data and some parameters describing the overall evolution of air traffic and some background concentrations, which are all converted into a time series of near surface temperature changes.

A detailed description of the methodology is given in Sect. 2. The atmospheric input data, derived from detailed climate-chemistry simulations employing idealised emission scenarios, are described in Sect. 3. These form the basis for the linearisation of chemical and radiative responses. A validation of the AirClim model is given in Sect. 4 by comparing the calculated chemical and radiative changes to detailed climate-chemistry simulations. Several applications of the AirClim model are presented in Sect. 5.

\section{Methodology}

\subsection{Overview}

An overview of the methodology is given in Fig. 1. The main part of the model AirClim is indicated in blue, showing the functional chain from emissions (yellow) and precalculated

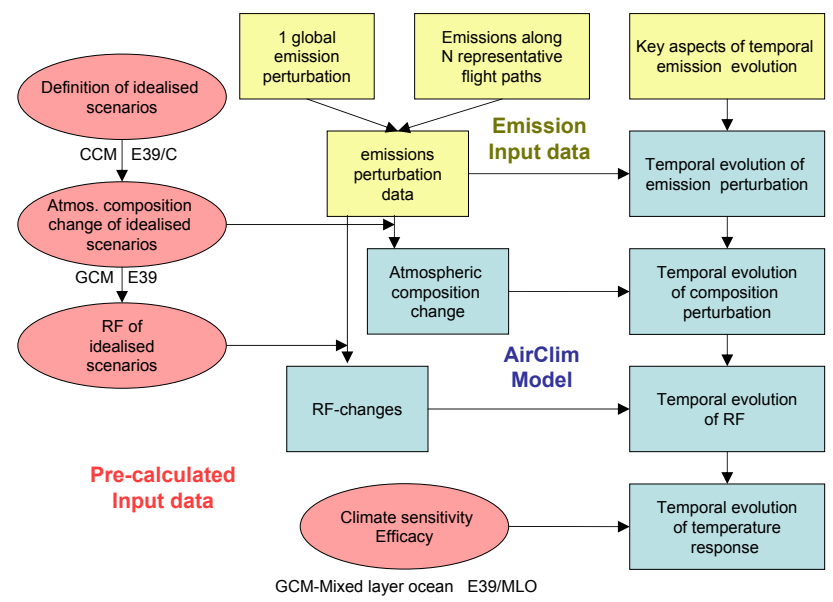

Fig. 1. Overview of the multi-step approach to derive near surface temperature changes and ozone depletion from emission scenarios.

Table 2. Latitudinal regions of idealised emission scenarios.

\begin{tabular}{llll}
\hline Latitude bands & Lat $_{\text {id }}$ & Description & Abbreviation \\
\hline $60^{\circ} \mathrm{N}-90^{\circ} \mathrm{N}$ & $75^{\circ} \mathrm{N}$ & Northern high latitudes & Pole \\
$30^{\circ} \mathrm{N}-60^{\circ} \mathrm{N}$ & $45^{\circ} \mathrm{N}$ & Northern mid-latitudes & MidLat \\
$30^{\circ} \mathrm{S}-30^{\circ} \mathrm{N}$ & $0^{\circ}$ & Tropical region & Tropic \\
$45^{\circ} \mathrm{S}-30^{\circ} \mathrm{S}$ & $37.5^{\circ} \mathrm{S}$ & Southern mid-latitudes & South \\
\hline
\end{tabular}

atmospheric input data (rose) to the resulting global mean near surface temperature change.

A more detailed description of the precalculated atmospheric input data is given in the next section. These data describe the Jacobian of the atmosphere-chemistry system with respect to emissions of $\mathrm{CO}_{2}, \mathrm{NO}_{\mathrm{x}}$, and $\mathrm{H}_{2} \mathrm{O}$, or in other words the atmospheric sensitivity to regional emissions.

\subsection{Precalculated input data}

In the first step we define emission regions with a normalised (=equal for all regions) emission strength (in mass mixing ratios per time). Then, in a second and third step chemical perturbations and radiative forcing of ozone, methane, water vapour, and contrails are calculated applying a state-ofthe-art climate-chemistry model (here: E39/C). These results are the precalculated atmospheric input data for AirClim. Within AirClim, they will be linearly combined with emission perturbation data (Sect. 2.3) to obtain perturbation patterns of chemical species and the associated radiative forcing (Sect. 2.4). 


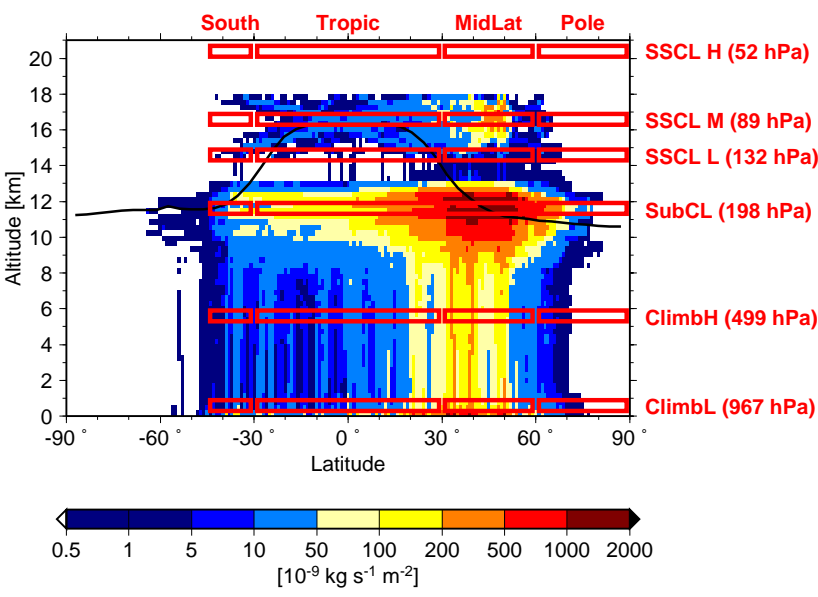

Fig. 2. Location of 24 emission regions used for the linearisation of perturbations of the atmospheric composition. Fuel consumption (zonally integrated) of a mixed fleet (SCENIC 2050 data) is underlaid for illustration $\left[\mathrm{kg} / \mathrm{s} / \mathrm{m}^{2}\right]$.

Table 3. Emission strength of idealised scenarios.

\begin{tabular}{ll}
\hline Species & Emission $\left[10^{-15} \mathrm{~kg} / \mathrm{kg} / \mathrm{s}\right]$ \\
\hline Fuel & $\mathrm{F}=100$ \\
$\mathrm{H}_{2} \mathrm{O}$ & $\mathrm{H}=125$ \\
$\mathrm{NO}_{\mathrm{x}}$ & $\mathrm{N}=0.45$ \\
\hline
\end{tabular}

\subsubsection{Idealised emission regions}

Emission regions are presented in Fig. 2 (see also Tables 1 and 2). We have defined areas for three potential supersonic cruise levels (SSCL) and three levels for subsonic air traffic, representing take-off, climb and cruise. Since the impact will depend on the geographical distribution, also 4 latitudinal bands are taken into account.

Since we mainly concentrate on supersonic (stratospheric) air traffic, we limited the number of subsonic flight levels. However, additional emission regions can easily be added to refine the methodology.

For each of the regions a uniform emission strength (in mixing ratio per time) is defined, which is derived from the SCENIC 2050 dataset: At $50^{\circ} \mathrm{N}$ the zonally integrated fuel consumption varies between 500 and $2000 \times 10^{-9} \mathrm{~kg} / \mathrm{s} / \mathrm{m}^{2}$ for subsonic cruise levels $(\approx 12 \mathrm{~km})$ and 200 and $500 \times 10^{-9} \mathrm{~kg} / \mathrm{s} / \mathrm{m}^{2}$ for supersonic cruise levels (18$19 \mathrm{~km})$. This relates to $62-247 \times 10^{-15} \mathrm{~kg} / \mathrm{kg} / \mathrm{s}$ and $77-$ $192 \times 10^{-15} \mathrm{~kg} / \mathrm{kg} / \mathrm{s}$, respectively. Mean values for emission strengths of 125 and $0.45 \times 10^{-15} \mathrm{~kg} / \mathrm{kg} / \mathrm{s}$ are chosen to represent these ranges (Table 3), respectively.
Table 4. Short description of the applied aircraft emission datasets.

\begin{tabular}{llllrr}
\hline & & & & \\
Project & Abbr. & Year & Description & Fuel [Tg/a] & EI(NO $\left.{ }_{\mathrm{x}}\right)$ \\
\hline TRADEOFF & & 2000 & Subsonic air traffic & 169 & 12.78 \\
SCENIC & S2 & 2025 & Subsonic air traffic & 393 & 12.97 \\
SCENIC & S4 & 2050 & Subsonic air traffic & 677 & 10.85 \\
SCENIC & S3 & 2025 & Mixed fleet & 393 & 12.42 \\
SCENIC & S5 & 2050 & Mixed fleet & 721 & 10.33 \\
SCENIC & S4core & 2050 & Subsonic w/o a/c & 659 & 10.85 \\
& & & to be replaced & & \\
\hline
\end{tabular}

\subsubsection{Chemical composition changes due to idealised emis-} sions

For each of the idealised emission regions, a climatechemistry simulation is performed employing normalised emissions of nitrogen oxides and water vapour to obtain its chemical response, i.e. the simultaneous effect of nitrogen oxides and water vapour. We applied the climatechemistry model E39/C (Hein et al., 2001), in which we accounted for full Lagrangian transport (ATTILA, Reithmeier and Sausen, 2002) of all species including water vapour and cloud water, which significantly improves the representation of stratospheric water vapour and temperatures (Stenke et al., 2008a). E39/C consists of the troposphere-stratosphere climate model ECHAM4.L39(DLR) (E39, Land et al., 1999) and the troposphere-stratosphere chemistry module CHEM (Steil et al., 1998). Recently, a number of revisions were released (Dameris et al., 2005). An overview of validation activities is given in Grewe (2006).

The experimental set-up comprises a steady-state simulation (time-slice) for the year 2050. This means that boundary conditions, like background $\mathrm{CO}_{2}, \mathrm{CH}_{4}, \mathrm{~N}_{2} \mathrm{O}$, and $\mathrm{CFC}$ concentrations, emissions of $\mathrm{NO}_{\mathrm{x}}$ from industry, biomass burning, transport, and soils and sea surface temperatures represent predicted conditions for the year 2050. They are prescribed according to scenario A1B (IPCC, 2001) or are taken from coupled ocean-atmosphere model simulations (sea surface temperatures). Background aircraft emissions include subsonic aircraft (SCENIC-database, scenario S4, Rogers et al., (2008) ${ }^{1}$, see also Table 4). This defines a base case simulation. Twenty-four perturbation simulations, one for each emission region, are performed including an additional constant emission of $\mathrm{NO}_{\mathrm{x}}$ and $\mathrm{H}_{2} \mathrm{O}$ (see above). After a spin-up time, five consecutive years are calculated in order to obtain annual mean changes.

Figure 3 shows exemplarily for the two emission regions SSCL-H/Pole (=polar high supersonic cruise levels, top figures) and SSCL-M/Pole (=polar middle supersonic cruise

\footnotetext{
${ }^{1}$ Rogers, H., Marizy, C., Pascuillo, E., Egelhofer, R., and Pyle, J.: Design options for future European supersonic transport, Atmos. Chem. Phys. Discuss., in preparation, 2008.
} 
Table 5. Radiative forcing $\left[\mathrm{mW} / \mathrm{m}^{2}\right]$ of various climate agents calculated with the climate-chemistry model E39/C (from Grewe et al., 2007) and the linearised model AirClim for the difference in the scenario S5 minus S4, i.e. mixed super- and subsonic fleet minus subsonic fleet for the year 2050.

\begin{tabular}{lccclc}
\hline & $\mathrm{H}_{2} \mathrm{O}$ & $\mathrm{O}_{3}$ & $\mathrm{CH}_{4}$ & Contrails & Total \\
\hline E39/C & 17.7 & 0.3 & -3.3 & -0.6 & 14.1 \\
AirClim & 17.3 & 0.2 & -2.0 & -0.4 & 15.1 \\
\hline
\end{tabular}

levels, bottom figures) changes in water vapour (left), nitrogen oxides $\left(\mathrm{NO}_{\mathrm{y}}, \mathrm{mid}\right)$, and ozone (right). Water vapour (left) shows an increase of around $150 \mathrm{ppbv}$ and $100 \mathrm{ppbv}$ at high northern latitudes for high and mid supersonic cruise levels, which corresponds to an increase of around 9 and $6 \%$, respectively. In the stratosphere the loss processes are similar for water vapour and nitrogen oxides $\left(\mathrm{NO}_{\mathrm{y}}\right)$ perturbations. Therefore the lifetimes and hence the change pattern of the perturbations are almost identical in the stratosphere. The impact on ozone (Fig. 3, right) strongly depends on altitude and latitude of the perturbation. The climatechemistry model E39/C shows a transition from ozone increase to ozone decrease roughly $4 \mathrm{~km}$ above the tropopause for the case of the mid supersonic cruise level (bottom). Ozone decrease is the stronger the higher the emissions occurs (top). The decrease in stratospheric ozone is compensated by a tropospheric increase as seen in the simulation for the mid supersonic cruise level (bottom).

\subsubsection{Contrail coverage}

Contrail coverage is calculated by folding the potential contrail coverage (Fig. 4) with flight data. The potential contrail coverage is the maximum possible coverage in the case that aircraft are flying everywhere at any time. It is calculated with E39/C including a parameterisation for line-shaped contrails (Ponater et al., 2002). According to Sausen et al. (1998) a linear scaling including a non-physical parameter (see also below) folded with the flown distance provides the actual coverage. Contrails may occur in regions, which are both cold and humid enough so that additional water vapour leads to cloud formation (Fig. 4). These regions are limited to the tropopause area (see thick line for the location of the tropopause). The effect of contrail-cirrus, i.e. spreading of linear-shaped contrail into a cirrus cloud is not taken into account. It could be included by a simple off-set factor to linear shaped contrails. However, since best estimates on the ratio between the climate impact of cirrus-contrails and lineshaped contrails are not available, we have disregarded the contrail-cirrus effect, which is regarded to be a minor source of uncertainty with respect to a partial replacement of subsonic by supersonic aircraft (Stenke et al., 2008a).

\subsubsection{Radiative forcing of idealised perturbation scenarios}

To each of the perturbation scenarios the stratospheric adjusted radiative forcing is calculated for ozone and water vapour changes, using the E39 model. Simulations are performed with a length of 15 months which include the annual mean perturbation patterns derived from the chemical composition change simulations (Sect. 2.2.2). The annual mean is calculated based on the last 12 months.

\subsubsection{Climate sensitivity and efficacies}

Although changes in chemical species may lead to the same radiative forcing their impact on climate (temperature) may differ significantly (Stuber et al., 2001; Joshi et al., 2003). This relationship is expressed in terms of climate sensitivity, i.e. the change in near surface temperature relative to a normalised radiative forcing $\left(1 \mathrm{~W} / \mathrm{m}^{2}\right)$ or in terms of efficacies (Hansen et al., 2005), which are the respective climate sensitivity parameters normalised to that of $\mathrm{CO}_{2}$. Efficacies for a variety of climate agents are taken from Ponater et al. (2005, 2006). The climate sensitivities used in this study are identical to those in Grewe et al. (2007) (their Table 7). (1 for $\mathrm{CO}_{2}, 1.18$ for $\mathrm{CH}_{4}, 1.4$ for $\mathrm{O}_{3}, 0.59$ for contrails, and 1.14 for $\mathrm{H}_{2} \mathrm{O}$ ). To all of these parameters an uncertainty range is taken into account (see Sect. 2.4.3 for more details)

\subsection{Emission data}

The aim of the application of the model AirClim is to compare technological options for aircraft with respect to climate change. Hence, at least three emission dataset are needed: A base case scenario and two scenarios which include perturbations or technological options to the base case and which are aimed to be intercompared. The difference to the base case represents the climate impact of the regarded technology option.

In principle two approaches are applicable. If enough knowledge is available on the future development of the considered fleet, then 3-D distributions of emissions of the base case and the perturbations can be used, i.e. this refers to the case of normal passenger aircraft, where present air traffic is well known and estimates for future traffic exist (e.g. Rogers et al., 2008 ${ }^{1}$ ). However, in the case of business jets, even nowadays traffic is only poorly known and future developments are even less explored. In this case, we suggest to take an arbitrary base case (e.g. Rogers et al., 2008 ${ }^{1}$ ). For a perturbation scenario emissions are added to the base case. These emissions are based on flight paths for city pairs, which should be somehow equally distributed over the globe. These city pairs are used for all technology options considered. A linear combination (to differently weight each region) of the emissions along the flight paths is used as an estimate for the considered fleet emissions. The weighting of the regions, i.e. the linear combination is somehow arbitrary 

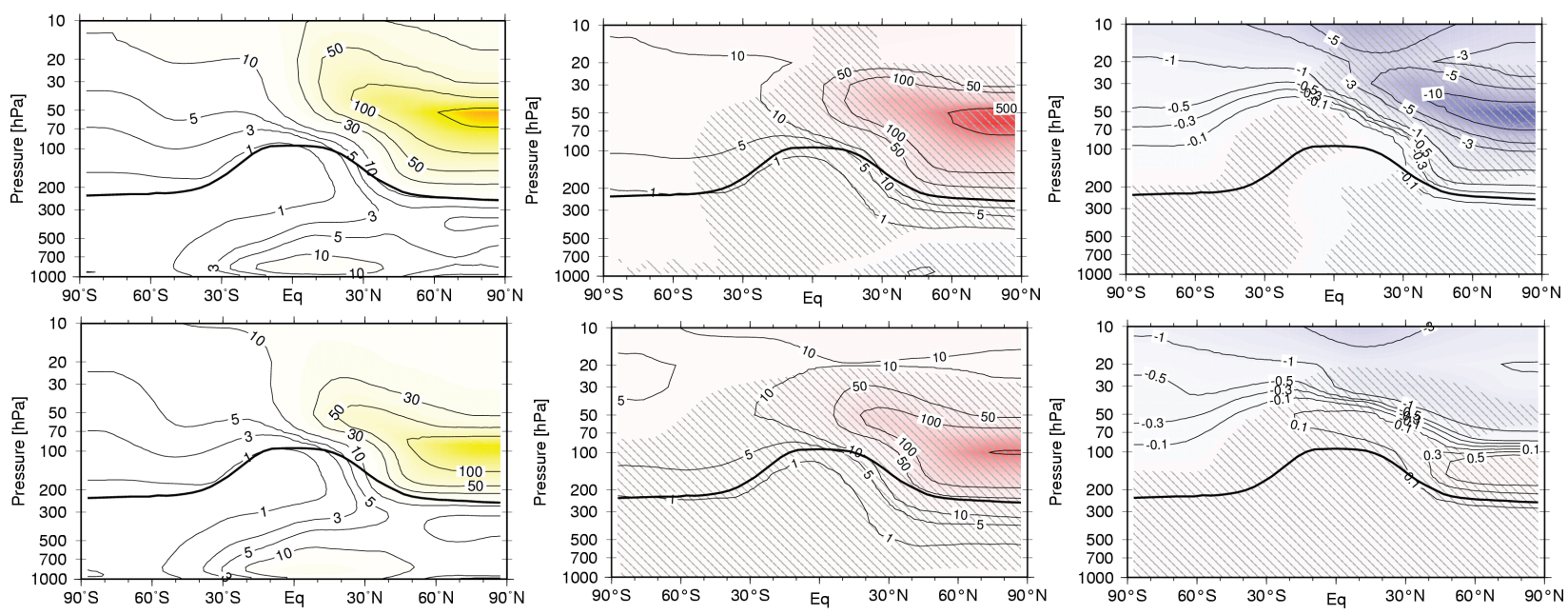

Fig. 3. Annual mean changes in zonal mean water vapour (left) [ppbv], nitrogen oxides $\left(\mathrm{NO}_{\mathrm{y}}\right)$ (mid) [pptv], and ozone (right) [ppbv] for polar emissions at high (top) and mid (bottom) supersonic cruise levels, i.e. for the regions SSCL-H/Pole and SSCL-M/Pole. Emission rates of 125 and $0.45 \times 10^{-15} \mathrm{~kg} / \mathrm{kg} / \mathrm{s}$ are used for water vapour and nitrogen oxides. Water vapour changes are all significant at a $95 \%$ level; significant changes at a $95 \%$ level are hatched for other species. The thick black line indicates the thermal tropopause.

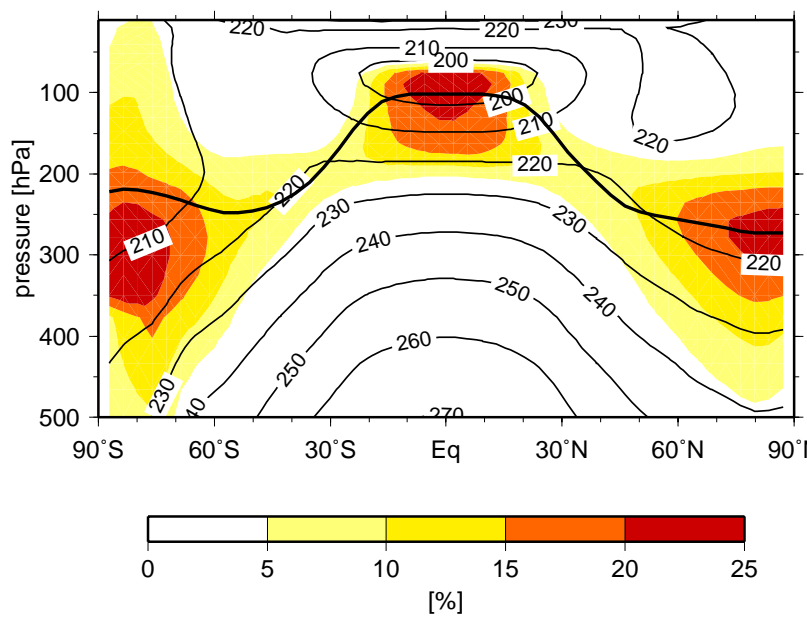

Fig. 4. Annual mean potential contrail coverage [\%] for 2050 (colour pattern). Thin lines show annual mean temperatures [K] and the thick line shows the location of the tropopause.

and should therefore be object to an uncertainty analysis. In all cases at least 3 three-dimensional emission datasets are considered and serve as input to the model AirClim.

In addition, a general temporal development of the base case air traffic has to be considered to take into account accumulation effects, e.g. of $\mathrm{CO}_{2}$ emissions. Further, a year has to be defined, when the technology options are taken in service and a year $\left(T^{\text {const }}\right)$ for which the 3-D emission data discussed above are representative (here: $T^{\text {const }}=2050$ ). For the present investigation, we suggest to keep the emissions constant for all scenarios after this date. One reason is that the composition change simulations (see Sect. 2.2.2) are 5 year steady-state simulations and hence are based on constant emissions. Further this date is far in the future (2050) so that projections are highly uncertain, anyway. However, other scenarios may well be taken into account. In any case, the impact of this assumption about emissions is somehow limited, since all scenarios are compared to the base case in the end.

\subsection{Linear response model: AirClim}

The model AirClim (see Fig. 1) combines the precalculated (Sect. 2.2) altitude and latitude dependent perturbations with the emission data (Sect. 2.3) in order to calculate composition changes and near surface temperature changes caused by these emissions.

\subsubsection{Transient emissions, concentration and radiative forcing changes}

The development of the base case $\mathrm{CO}_{2}$ emission and concentration changes are defined by input parameters to the model AirClim. $\mathrm{CO}_{2}$ emissions of the perturbation scenarios are calculated by integrating the emissions along the flight paths or an individual emission dataset. Thus they are representative for the year $T^{\text {const }}$. Between the time of in-service and $T^{\text {const }}$ global and annual mean $\mathrm{CO}_{2}$ emission values are derived by exponential interpolation in-between, which results in a time series of changes in $\mathrm{CO}_{2}$ emissions. The resulting changes in the concentration of $\mathrm{CO}_{2}$ are calculated 


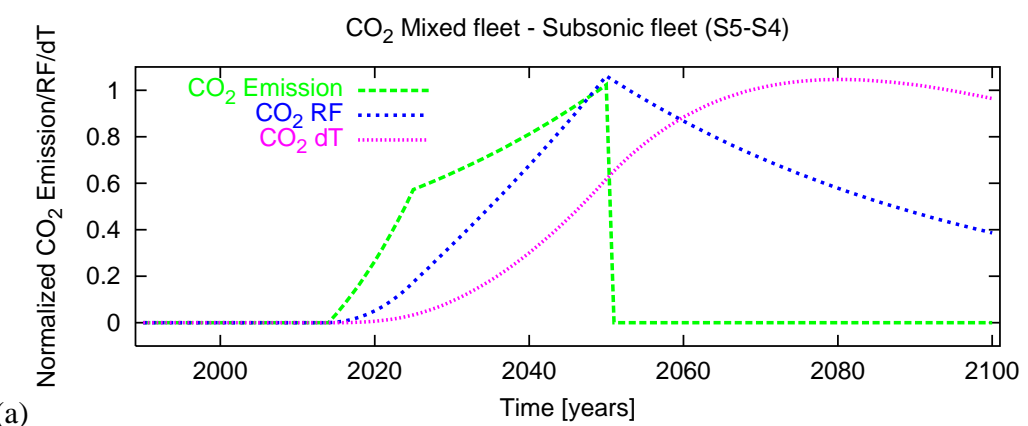

(a)

Radiative Forcing: Mixed fleet - Subsonic fleet (S5-S4)

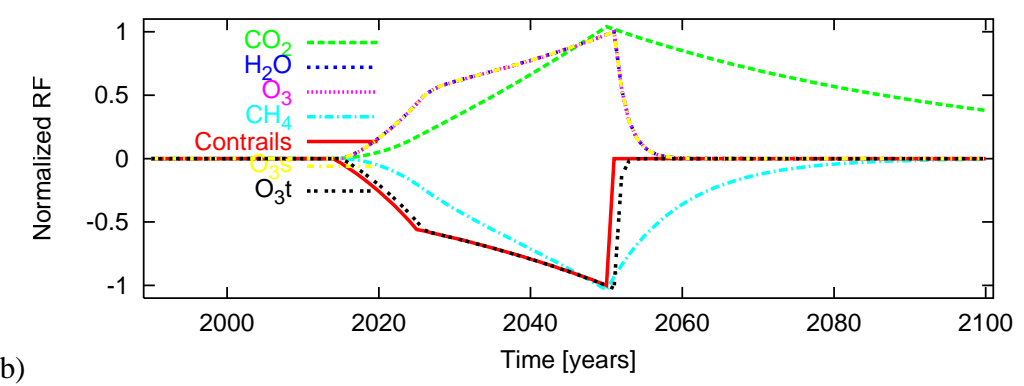

(b)

Normalized temperature change: Mixed fleet - Subsonic fleet (S5-S4)

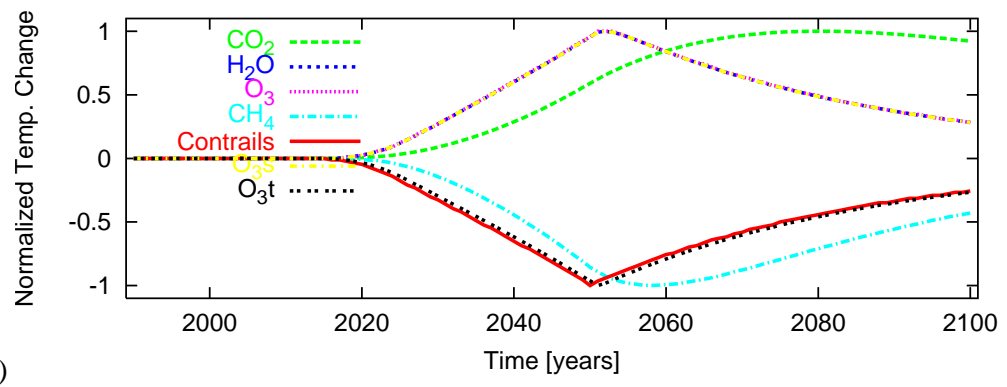

Fig. 5. Non-dimensional temporal development of (a) $\mathrm{CO}_{2}$ emissions (b) radiative forcing and (c) temperature for a supersonic fleet (here: SCENIC S5 mixed fleet minus subsonic fleet S4). Emissions are switched off from 2050 onwards to illustrate decay times. All curves are normalised to 1 for their maximum values to illustrate the behaviour of each species. Ozone is split into a stratospheric $\left(\mathrm{O}_{3} \mathrm{~s}\right)$ and tropospheric part $\left(\mathrm{O}_{3} \mathrm{t}\right)$. Curves for water vapour, ozone and stratospheric ozone are overlaid.

using response functions with 5 different lifetimes to represent its complex behaviour according to Sausen and Schumann (2000).

The concentration changes of all other species are calculated as follows. First a concentration change is calculated by combining the results of the pre-calculated idealised emission scenarios with the emission data. This calculated concentration change is only representative for a certain time, namely the date of the 3D-emission dataset. In a second step the temporal evolution of concentration changes are calculated based on the nature of the species. For short-lived species (e.g. contrails), the concentration change is linked to the $\mathrm{CO}_{2}$ emissions. For longer-lived species $X$ (water vapour, ozone) the evolution is described by a linear differential equation $\frac{d \Delta C^{\text {specie }}}{d t}=s P(t)-\tau^{-1} \Delta C^{\text {specie }}$

which includes a lifetime $\tau$, deduced from the idealised scenarios (see below). $P$ is a production term, derived from adequate emissions, e.g. $\mathrm{CO}_{2}$ emissions for water vapour, or $\mathrm{NO}_{\mathrm{x}}$ for ozone. This factor $s$ is chosen so that the solution of the differential equation at time $T^{\text {const }}+\tau_{\text {species }}$ equals the concentration change calculated in the first step. The time for which this concentration change is representative is approximately $T^{\text {const }}+\tau_{\text {species }}$ with $\tau_{\text {species }}$ the perturbation lifetime of the respective species. This describes the general approach. A more detailed description is given in the following. 
In detail, the concentration changes of a species $C^{\text {species }}$ (e.g., ozone and water vapour) for a perturbation scenario are calculated by folding the emissions along the flight paths with the precalculated scenarios:

$C^{\text {species }}=\frac{1}{T} \int_{0}^{T} \frac{E^{\text {species }}(t)}{X} \sum_{k} \frac{\epsilon_{k}(t) C_{i d}^{\text {species }}\left(i_{k}, j_{k}\right)}{M\left(i_{k}, j_{k}\right)} d t$,

where $\epsilon_{k}(t)(k=1, \ldots, 4)$ are weights for the four surrounding emissions regions $\left(i_{k}, j_{k}\right)\left(i_{k}=\right.$ latitude, $j_{k}=$ pressure level) at a certain point of the flight path, $C_{i d}^{\text {species }}\left(i_{k}, j_{k}\right)$ the concentration change in $[\mathrm{kg} / \mathrm{kg}]$ from the idealised scenario $\left(i_{k}, j_{k}\right)$ (Tables 1 and 2$), M\left(i_{k}, j_{k}\right)$ the respective mass of air in the idealised emission region in $[\mathrm{kg}]$, and $E^{\text {species }}(t)$ the emission of species in $[\mathrm{kg} / \mathrm{s}]$. Note that $C^{\text {species }}$ and $C_{i d}^{\text {species }}\left(i_{k}, j_{k}\right)$ are 2 -dimensional fields. $X$ is the respective normalised emission strength (Table 3$) . X \times M\left(i_{k}, j_{k}\right)$ then gives the emission rate (in $\mathrm{kg} / \mathrm{s}$ ) in the idealised emission region. Equation (2) describes a temporal integral of an individual flight path ( $\mathrm{t}$ is the time an aircraft flies). In the case of an 3D emission dataset, e.g., as in TRADEOFF or SCENIC, this integral has to be extended by a spatial integration.

Other quantities are derived in a similar way, e.g. the radiative forcing, changes in methane lifetime, the perturbation lifetimes of tropospheric ozone and stratospheric quantities are derived by replacing $C_{i d}^{\text {species }}$ in Eq. (2) by the radiative forcing $R F_{i d}^{\text {species }}$, etc. The $100 \mathrm{hPa}$ level is used for the separation between troposphere and stratosphere. A climatological tropopause based on temperature profiles would be feasible, however emissions in the lowermost stratosphere have also a limited lifetime, which is more similar to the upper troposphere than mid stratosphere.

The change in methane is derived by regarding the difference of two linear differential equations (for details see Appendix A) for background methane $\left(\mathrm{C}^{\mathrm{CH}_{4}}\right)$ and the perturbation $\left(C^{\mathrm{CH}_{4}}+\Delta C^{\mathrm{CH}_{4}}\right)$, which both have the same production terms and the loss differs by the change in methane lifetime, resulting in

$\frac{d}{d t} \Delta C^{\mathrm{CH}_{4}}=\frac{\delta}{1+\delta} \tau_{\mathrm{CH}_{4}}^{-1} C^{\mathrm{CH}_{4}}-\frac{1}{1+\delta} \tau_{\mathrm{CH}_{4}}^{-1} \Delta C^{\mathrm{CH}_{4}}$,

where $\delta$ is the relative change in lifetime, $\tau_{\mathrm{CH}_{4}}$ the methane perturbation lifetime (here: 12 years) and $C^{\mathrm{CH}_{4}}$ the background methane concentration, e.g. taken from IPCC (2001, 2007). A temporal evolution of the change of the methane lifetime is achieved by scaling it with normalised $\mathrm{NO}_{\mathrm{x}}$ emissions $\left(E^{\mathrm{NO}_{\mathrm{x}}}(t) / E^{\mathrm{NO}_{\mathrm{x}}}\left(T_{\text {const }}+\tau_{\mathrm{CH}_{4}}\right)\right)$, such that $\delta\left(T^{\text {const }}+\right.$ $\left.\tau_{\mathrm{CH}_{4}}\right)=\delta$.

In principle, changes in contrail coverage can be estimated applying the identical methodology as for ozone and water vapour (Eq. 2). However, contrail occurrence is more constrained to altitudes around the tropopause (see Fig. 4), which requires a higher vertical resolution of the idealised scenarios than currently performed. Therefore, we suggest
Table 6. Radiative forcing $\left[\mathrm{mW} / \mathrm{m}^{2}\right]$ of various climate agents calculated with the E39/C model (Grewe et al. (2002) for ozone and methane and Marquart et al. (2003) for contrails), by Sausen et al. (2005) and by applying the linearised model AirClim for subsonic air traffic emission data. ${ }^{\dagger}$ Results are scaled with fuel consumption (factor 1.25) to obtain values for 2000 as done in Sausen et al. (2005). ${ }^{*}$ The sum differs slightly from the total value in Sausen et al. (2005), because soot and sulphate contributions to radiative forcing are excluded. + RF due to methane changes are based on steady state simulations in many publications, e.g. Sausen et al. (2005); IPCC (1999). Since in AirClim the changes in methane lifetime and its impact on concentration and RF are taken into account a time shift occurs ( $\approx 10$ years). The first value shows the RF calculated with the method used in Sausen et al. (2005) whereas the second shows the actual AirClim value.

\begin{tabular}{lllllll}
\hline & $\mathrm{CO}_{2}$ & $\mathrm{H}_{2} \mathrm{O}$ & $\mathrm{O}_{3}$ & $\mathrm{CH}_{4}$ & Contrails & Sum* \\
\hline E39/C-1992 & & & 12.5 & -6.6 & 3.5 & \\
E39/C-2000 & & & 15.6 & -8.3 & 4.5 & \\
AirClim & 24.4 & 2.2 & 17.8 & $-8.3^{+}(-6.0)$ & 5.8 & $42.0^{+}(44.3)$ \\
Sausen et al. & 25.3 & 2.0 & 21.9 & -10.4 & 10.0 & $48.8^{*}$ \\
\hline
\end{tabular}

here an alternative method. The potential contrail coverage presented in Fig. 4 is used and linearly folded with data of flown distance, which leads to a 2-D contrail coverage (see also Sect. 4 and Fig. 7c, e). The advantage is that the horizontal and vertical resolution is much better resolved with $48 * 39=1872$ gridpoints, given by the resolution of E39/C, compared to 24 if only the idealised scenarios are applied. Global total contrail coverage is calculated by vertical summation taking into account maximum random overlap (Manabe and Strickler, 1964). The non-physical scaling parameter $\gamma=0.00166 \mathrm{~s} \mathrm{~m}^{2} / \mathrm{km}$ is chosen such that the global value is identical to a reference 3-D GCM simulation (see below) applying the SCENIC database. Contrail radiative forcing is calculated by applying a linear relationship between global mean contrail coverage and radiative forcing: $63.84 \frac{\mathrm{mW}}{\mathrm{m}^{2}}$ for $1 \%$ total contrail coverage (Stenke et al., 2008b).

\subsubsection{Temperature change}

The temperature change caused by the perturbation scenarios is calculated following the approach of Sausen and Schumann (2000):

$$
\Delta T=\int_{t_{0}}^{T} G\left(t-t^{\prime}\right) \mathrm{RF}^{*}\left(t^{\prime}\right) d t^{\prime},
$$

with

$$
\begin{aligned}
G\left(t-t^{\prime}\right)= & \alpha e^{-\frac{t-t^{\prime}}{\tau}}, \text { with } \\
& \alpha=2.246 / 36.8 \frac{\mathrm{K}}{\mathrm{a}} \text { and } \tau=36.8 \mathrm{a} \text { and } \\
\mathrm{RF}^{*}(t)= & \sum_{\text {species }} \frac{\mathrm{RF}^{\text {species }}}{\mathrm{RF}^{\mathrm{CO}}{ }_{2}} \lambda_{\text {species }}^{\text {eff }} \frac{\Delta C_{i}(t)}{C^{\text {species }}}
\end{aligned}
$$


$\Delta T$ describes the perturbation temperature with respect to the base case, $G$ the Green's function for the near surface temperature response and $\mathrm{RF}^{*}$ the normalised radiative forcing. The response time $\tau$ includes the response of the surface layer and the deep ocean and differs from some other approaches using a mixed layer ocean model (Shine et al., 2005b) with considerably smaller response times. $\lambda_{\text {species }}^{\text {eff }}$ are the efficacies for individual species, i.e. the climate sensitivity parameter of a species normalised with that of $\mathrm{CO}_{2}$. $\overline{C^{\text {species }}}$ represents the global mean mixing ratio.

In order to illustrate the relationship between emission, radiative forcing and temperature change, as well as the impact of different lifetimes of atmospheric tracers, a thought experiment is given in Fig. 5. We consider an increase in emissions up to the year 2050 and switch them off afterwards (Fig. 5a). A supersonic impact scenario is taken as emission scenario, i.e. the SCENIC mixed fleet minus subsonic fleet scenario (Grewe et al., 2007) (S5-S4), where the first HSCT aircraft are in service (and replace subsonics) in 2015, a second generation evolves in 2025 and the full fleet is established in 2050. Again for illustrative reasons, all time series are normalised to their maximum values. Note that since we consider an aircraft replacement scenario negative effects may occur, e.g. in the case of contrails. Figure 5a illustrates the relation between $\mathrm{CO}_{2}$ emissions, radiative forcing and temperature changes. The radiative forcing from $\mathrm{CO}_{2}$ slowly decreases after 2050, mirroring the relatively long lifetime of $\mathrm{CO}_{2}$ perturbations. Temperature increase peaks much later (around 2080) caused by the inertia of the ocean-atmosphere system.

Other species show different behaviour for radiative forcing (Fig. 5b) (and their concentration, not shown) and the associated temperature increase (Fig. 5c) according to the lifetime of the regarded species: Contrails and tropospheric ozone have shorter lifetimes, hence radiative forcing decreases more rapidly than that of stratospheric water vapour, methane and $\mathrm{CO}_{2}$. Maximum temperature changes for contrails and tropospheric ozone changes are found around 2050, whereas methane peaks around 2060 and $\mathrm{CO}_{2}$ around 2080.

\subsubsection{Uncertainties}

A number of processes are included in the calculation of the near surface temperature change. All of these processes are known only within a range of uncertainty. The AirClim model includes the possibility to give mean values and ranges. The lifetimes of tropospheric or stratospheric perturbations are calculated (Sect. 2.4.1) depending on the regarded 3-D emissions. For the lifetime of a stratospheric perturbation an uncertainty range of $\pm 40 \%$ is regarded following Grewe et al. (2007), whereas for the troposphere only $\pm 20 \%$ are taken into account, since model uncertainties in e.g. simulating tropospheric ozone lifetimes agree within this range (Stevenson et al., 2006). Radiative forcing calculations are also combined with an uncertainty range of $\pm 5 \%$ for
$\mathrm{CO}_{2}, \pm 10 \%$ for $\mathrm{CH}_{4}, \pm 30 \%$ for $\mathrm{O}_{3}$ and $\pm 50 \%$ for $\mathrm{H}_{2} \mathrm{O}$. Uncertainty ranges for efficacies follow IPCC (2007) and Joshi et al. (2003) with values of $\pm 30 \%$ for $\mathrm{O}_{3}$ and $\mathrm{H}_{2} \mathrm{O}$ and $\pm 10 \%$ for $\mathrm{CH}_{4}$ and contrails. In general, efficacies show smaller variations among models than climate sensitivity parameters (Joshi et al., 2003). The variability within modeled efficacies varies by approximately less than $\pm 30 \%$. For example tropospheric ozone efficacies vary roughly between 0.7 and 1.1 (IPCC, 2007), for lower stratospheric ozone between 1.2 and 1.8 (Joshi et al., 2003), and for methane between 1.1 and 1.2 (Hansen et al., 2005; Ponater et al., 2006).

This leads to a number of possible parameter settings. For each an AirClim simulation is performed to obtain an uncertainty range of the results.

\section{Atmospheric sensitivity to emissions}

In the previous section the methodology has been described. An important part are the pre-calculated input data. These represent the atmospheric sensitivity to regional emissions. 25 simulations ( 1 base case and 24 perturbations, see Fig. 2 and Sect. 2.2.1) were performed with the climate-chemistry model E39/C for each of the selected emission region. Since the emission regions do not have the same air mass, the results presented in Fig. 3 are not directly intercomparable. In contrast, the lifetimes of the perturbations, i.e. the mass of the perturbation divided by the emission strength are directly intercomparable.

Figure 6a shows the lifetimes of the perturbations for every emission region. For the polar region the water vapour perturbation has a lifetime of 13 months, whereas at lower altitudes the lifetime decreases to 9 and 4.3 months for the mid and low supersonic cruise altitude. At subsonic cruise levels the lifetime of a water vapour perturbation amounts to around 1 month and is less than $1 \mathrm{~h}$ for climb and take-off.

Changes in ozone and water vapour have an impact on the concentration of the hydroxyl radical $(\mathrm{OH})$. The reaction of $\mathrm{OH}$ with methane $\left(\mathrm{CH}_{4}\right)$ is the dominant tropospheric methane loss process. Although methane changes are calculated in the idealised scenarios, they do not represent the steady-state methane change, basically for two reasons. First, methane has a lifetime of around 12 years (IPCC, 2001, 2007), which implies that a simulation length longer than 5 model years is necessary to accurately calculate methane changes. Second, at the surface, methane is prescribed to correctly represent tropospheric methane. This offsets the calculated methane changes to some extend. For that reason methane loss rates from the reaction with the hydroxylradical $(\mathrm{OH})$ are calculated and converted into a methane perturbation lifetime. Additionally, a factor of 1.4 is taken into account for reductions in the loss rates due to the lower boundary condition (IPCC, 1999). Figure 6b shows relative changes $(\%)$ in tropospheric methane lifetime for the 24 emission regions compared to the background simulation. 

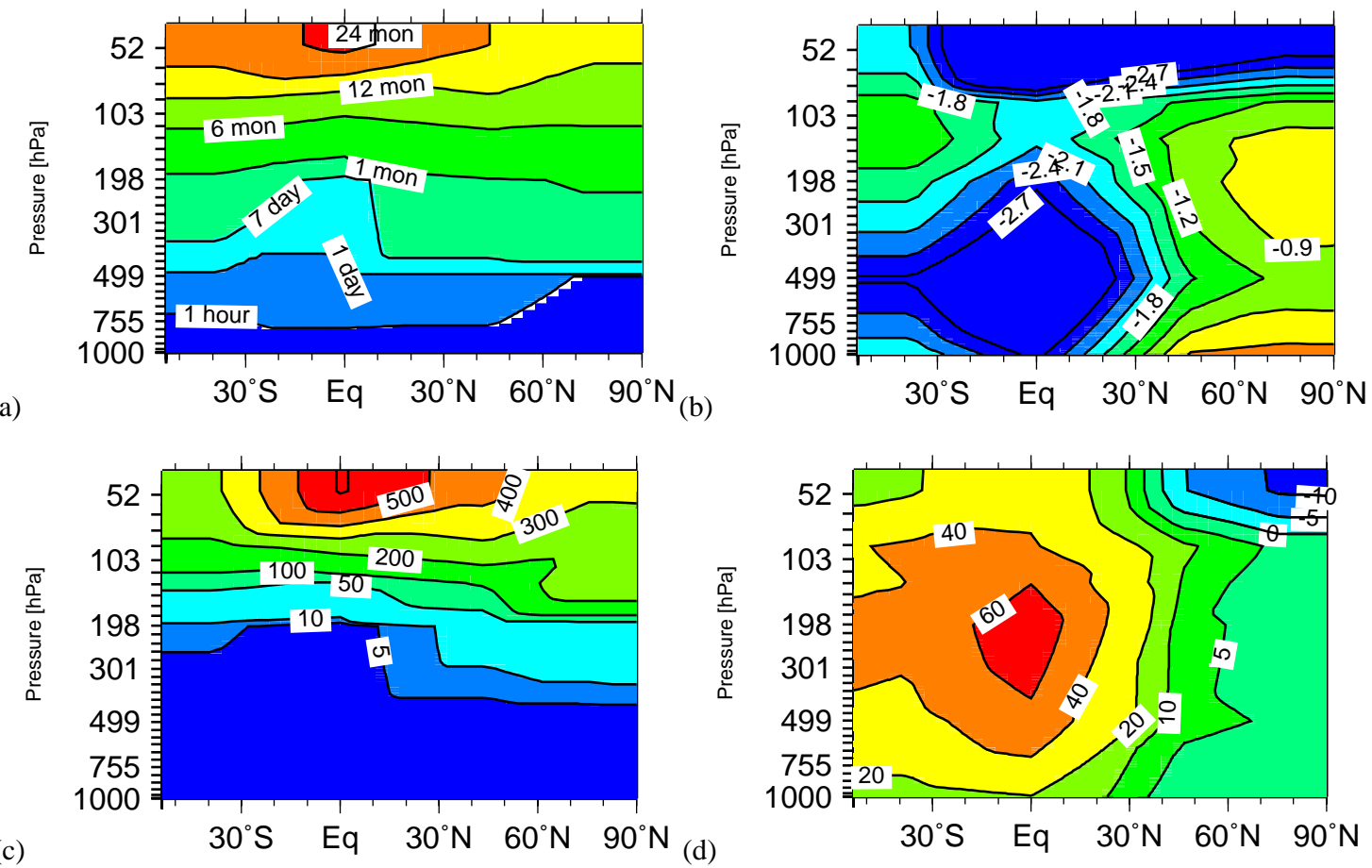

(c)

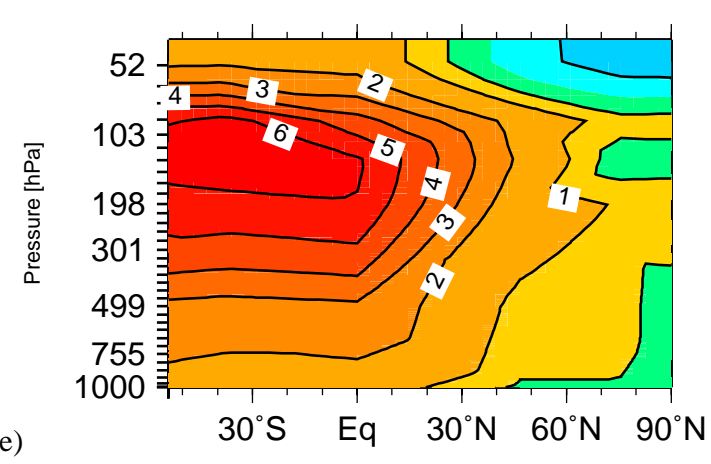

Fig. 6. Water vapour perturbation lifetime (a), methane lifetime change [\%] (b), and radiative forcing at the tropopause for the water vapour (c) and ozone perturbations (d) normalised to the same total annual emission of $1 \mathrm{Pg}$ water vapour and $1 \mathrm{TgN}$ of $\mathrm{NO}_{\mathrm{y}}$ in $\mathrm{mW} / \mathrm{m}^{2}$. (e) $\mathrm{Negative}$ ratio between ozone and methane radiative forcing.

Two regions can be identified, where an emission of $\mathrm{NO}_{\mathrm{x}}$ reduces methane lifetime most: The stratosphere at high supersonic cruise level, as already indicated in the results of the ozone change (see above) and the tropical troposphere $(-2.7 \%$ change in methane lifetime at $500 \mathrm{hPa}$ and $-2.5 \%$ at $200 \mathrm{hPa}$ for $1 \mathrm{TgN} / \mathrm{year}$ emitted), where chemistry is fast and reacts more sensitively to emissions. Minimum changes are found at tropopause levels, where chemistry is generally slow and $\mathrm{OH}$ formation limited by either water vapour concentration or UV irradiance.

Figures $6 c, d$ present the adjusted radiative forcing at the tropopause for water vapour and ozone scaled to a normalised emission of $1 \mathrm{Pg} \mathrm{H}_{2} \mathrm{O}$ and $1 \mathrm{TgN}$ per year, respectively. The effects from water vapour emissions qualitatively follow the pattern of the respective lifetime (Fig. 6a) and leads to a positive radiative forcing independent of the location of the emissions. In the extra-tropics, the sensitivity to the respective latitude of the emission is small, in comparison to ozone (Fig. 6d). $\mathrm{NO}_{\mathrm{x}}$ emissions show largest impact on ozone radiative forcing in the tropical upper troposphere with a large latitudinal gradient from $60 \mathrm{~mW} / \mathrm{m}^{2}$ per $1 \mathrm{TgN} /$ year emitted to less than $5 \mathrm{~mW} / \mathrm{m}^{2}$ at higher latitudes. In contrast, $\mathrm{NO}_{\mathrm{x}}$ emissions at high supersonic cruise altitude lead to a negative radiative forcing at mid and high latitudes.

The pattern of the regional dependency of ozone and methane radiative forcing differ, although they are both initiated by $\mathrm{NO}_{\mathrm{x}}$ emissions. This is illustrated by Fig. 6e, which shows the ratio between both forcings (ozone to methane). Maximum values are found in the tropical tropopause region, decreasing towards lower altitudes and higher latitudes. 
It reflects regional differences in the chemical response to a $\mathrm{NO}_{\mathrm{x}}$ emission. And further, since ozone and methane have considerably different lifetimes, they disperse differently and hence have a different impact on radiation. The radiative forcing of ozone changes at high latitudes is smaller compared to tropical ozone changes of the same amount (Joshi et al., 2003). Whereas methane changes show a more uniform pattern than ozone because of the longer perturbation lifetime of methane compared to ozone.

We are not aware that similar studies were performed before, i.e. investigating the impact of regional high altitude emissions (in contrast to surface emissions, e.g. Fuglestvedt et al., 1999) on climate. However, the impact of regionally and vertically varying ozone changes on RF was investigated and found to agree among models within \pm 25 to $30 \%$ (Joshi et al., 2003).

\section{Validation of the linearisation approach}

The basic question is, whether the linearisation of the effect of emissions on the chemical composition and contrail coverage is applicable. This is a necessary prove of concept before AirClim can be applied to aircraft emissions. This is investigated by comparing results from a detailed climate-chemistry simulation (E39/C) with the results of the linearised model AirClim. In the detailed simulation, E39/C is applied to calculate ozone, water vapour and contrail cover changes and the associated radiative forcing. In the linearised approach the precalculated perturbations of the chemical composition and contrail cover as well as their respective radiative forcing are folded with the emission data set. Two verification approaches are presented in the following: A supersonic test case (Sect. 4.1), including an intercomparison of composition changes and radiative forcing and a subsonic test case (Sect. 4.2), which is concentrating on radiative forcing only.

\subsection{Supersonic test case}

The first verification is based on a supersonic application. Two simulations for each model (E39/C and AirClim) are performed, one including emissions of water vapour and nitrogen oxides from a subsonic fleet and another one, which includes emissions from a mixed sub- and supersonic fleet (S5-S4; SCENIC database, see Table 4). In the mixed fleet (S5), 500 subsonic aircraft are replaced by supersonics in a way that the passenger transport volume is unaffected. A more detailed discussion of the chemical impacts is given in Grewe et al. (2007) and a discussion of the contrail impacts in Stenke et al. (2008b). Here we concentrate on the differences between the detailed and the linearised approach.

Figure 7 shows the results for E39/C (top) and AirClim (bottom) for the difference of the two model simulations, i.e. the impact of a partial replacement of subsonic aircraft by supersonics. (S5-S4; SCENIC database, see Table 4).
Clearly, magnitude and pattern of the change in water vapour (left) is similar in both models. Maximum values of around $300 \mathrm{ppbv}$ are found in both models on the northern hemisphere at around $70 \mathrm{hPa}$, decreasing to around $30 \mathrm{ppbv}$ at tropopause altitudes. However, differences occur on tropical and southern latitudes, where the water vapour enhancement is overestimated by $50 \%$ in AirClim. Clearly, the low resolution in AirClim, where the whole atmosphere is resolved by 24 gridpoints compared to 180000 gridpoints in E39/C, leads to numerical diffusion. Note, that only radiative forcing values will further be taken into account for calculating temperature changes. I.e. radiative forcings are calculated by folding aircraft emission data with the radiative forcing of the idealised scenarios. They are not calculated from the concentration changes derived from the folding of aircraft emission data with the concentration changes of the idealised scenarios as presented in Fig. 7 (see also Fig. 1). Hence the calculation of the concentration perturbation pattern as shown in Fig. 7 are a useful validation, but are not required for calculation of the temperature changes.

Both models show a similar pattern in ozone changes (Fig. 7 middle column) caused by a partial substitution of subsonic air traffic. Ozone depletion peaks in the tropical stratosphere at around $10 \mathrm{hPa}$ and at northern mid-latitudes at around $50 \mathrm{hPa}$. In the troposphere a distinct difference is found between northern and southern hemisphere with a decrease and increase in ozone, respectively. Absolute values of ozone changes differ only slightly between the models.

Contrail formation changes for both models are shown in Fig. 7c, f. The global pattern is very similar in both simulations. A decrease in contrail coverage at mid-latitudes due to the replacement of subsonic aircraft is compensated by a tropical increase in contrail coverage. Both simulations show a good agreement of the pattern, e.g. an increase in contrail coverage at some subsonic cruise levels, i.e. where supersonic aircraft fly at subsonic speed (over land) to avoid sonic boom.

Table 5 shows the radiative forcing from the substitution of parts of a subsonic fleet by supersonics (SCENIC S5-S4 scenario) as calculated by Grewe et al. (2007) (top) and with the AirClim model. Clearly, water vapour, the dominant climate agent in this case, is well reproduced. Other parameters, which are an order of magnitude smaller show larger deviations. In general, the more complex the chemical and physical processes are the larger are the deviations. Water vapour is mainly dynamically controlled, whereas ozone and methane are dynamically and chemically controlled. The ozone effect is a residuum resulting from ozone depletion at higher altitudes and ozone increases below (Grewe et al., 2007). For methane, not only the more direct impact resulting from an increased $\mathrm{OH}$ formation via reaction $\mathrm{NO}+\mathrm{HO}_{2} \rightarrow \mathrm{OH}+\mathrm{NO}_{2}$ is leading to a decrease in methane lifetime, but also the increase in UV due to ozone depletion leads to an increased OH formation (Taalas et al., 1997; Isaksen et al., 2005; Grewe et al., 2007). As a consequence 

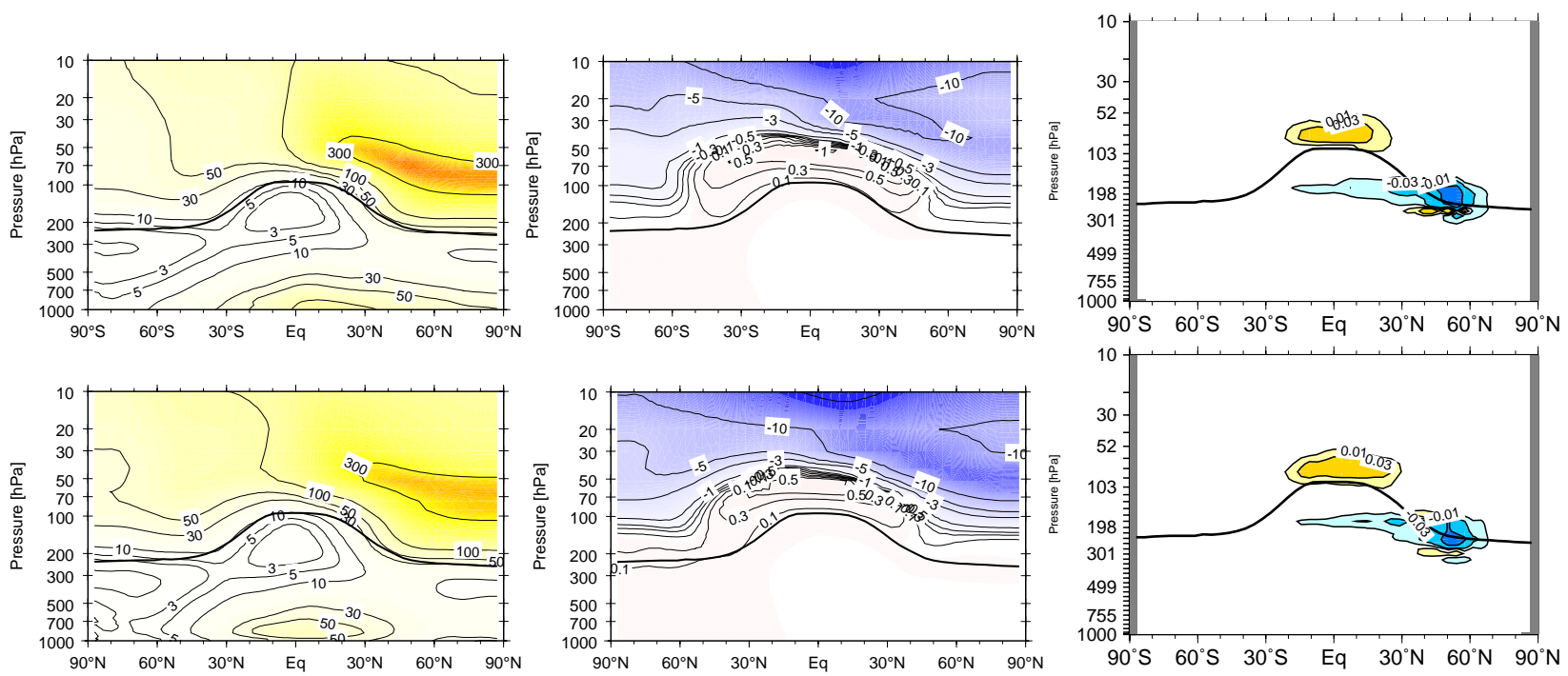

Fig. 7. Annual mean changes in water vapour (left) [ppbv], ozone (mid) [ppbv], and contrail coverage (right) [0.1\%] caused by a supersonic fleet (here: SCENIC S5 mixed fleet minus subsonic fleet S4). Top: Results derived with E39/C; Bottom: Calculated with AirClim. Thick lines indicate the location of the tropopause. Isolines for contrail changes are $-0.3,-0.1,-0.03,-0.01,0.01,0.03,0.1,0.3$.

methane lifetime shows a strong vertical gradient for stratospheric emissions (e.g. between 100 and $50 \mathrm{hPa}$ ), which leads to an underestimate of the methane lifetime changes in the AirClim model.

Hence the linearisation of transport, chemistry, contrail formation and radiation is working sufficiently well for the most important climate agents. A higher resolution is expected to lead to better representations of methane and ozone effects, which are, however, minor contributors in this case. The pattern and absolute values of concentration changes are well reproduced and the total radiative forcing agrees within less than $10 \%$ between the linearised model AirClim and the non-linear climate-chemistry model E39/C.

\subsection{Subsonic test case}

The second part of the verification concentrates on radiative forcing for the year 2000, resulting from subsonic air traffic. Hence in this case we are intercomparing the whole effect of air traffic, i.e. compared to a background without air traffic, which differs from the previous section. Ozone and methane radiative forcings can be intercompared with results obtained with the model E39/C (Sausen et al., 2005; Grewe et al., 2002) for 1992 and scaled to the year 2000 with the increase in fuel consumption (Table 6). Hence for a verification of RF results AirClim results have to be compared to the E39/C-2000 estimates. Ozone radiative forcing agrees within $15 \%$. Concerning methane, Sausen et al. (2005) as well as IPCC (1999) assumes steady-state perturbation to obtain the methane changes associated radiative forcing whereas in AirClim a lifetime change based on $\mathrm{OH}$ changes is estimated, which would become fully effective only after more than a decade due to the methane's lifetime of approximately 12 years. This leads to systematically different lower results for the AirClim model. Neglecting this transient behaviour, i.e. applying the same steady-state assumptions as in Sausen et al., we obtain good agreement of $-8.3 \frac{\mathrm{mW}}{\mathrm{m}^{2}}$.

Contrail radiative forcing agrees within $20 \%$, though, the underlying emission data sets differ (DLR-2 aircraft emission dataset used in the study by Marquart et al. (2003)), which inhibits a constrained verification of the linearisation approach. A direct intercomparison with the detailed modelling results obtained by Stenke et al. (2008a) can be performed. They calculated a contrail coverage of $0.372 \%$ for the SCENIC S4 subsonic fleet in 2050 and a associated radiative forcing of $24.7 \frac{\mathrm{mW}}{\mathrm{m}^{2}}$. With the same emission dataset we obtain with AirClim a coverage of $0.352 \%$ and a radiative forcing of $22.4 \frac{\mathrm{mW}}{\mathrm{m}^{2}}$, which is an agreement within $10 \%$, which indicates that half of the difference between the study by Marquart et al. (2003) and our results arise from the different emission datasets.

The comparison to other modelling results (Sausen et al., 2005) show larger differences (Table 6), which are in the range of $20 \%$ for ozone and methane, $40 \%$ for contrail and $15 \%$ in the total (Tab. 6). However, the values agree within the uncertainty ranges evaluated in IPCC (1999).

The only exception is the contribution from water vapour which is largely overestimated for subsonic applications. Figure $6 \mathrm{~b}, \mathrm{c}, \mathrm{d}$ show a small sensitivity of ozone and methane radiative forcing to the subsonic flight altitude, whereas for water vapour the sensitivity is very large. In the present state, the vertical resolution of AirClim is not sufficient to resolve the water vapour impact at tropopause regions. To obtain reasonable values for water vapour radiative forcing from 
subsonic air traffic we have divided the value by 3 for subsonic applications only to agree with Sausen et al. (2005). This non-physical tuning should only avoid misinterpretations of the figure and doesn't have any further implications. However for future investigations of subsonic air traffic this short-coming should be resolved. The water vapour impact is regarded to be small for subsonic air traffic, anyway (IPCC, 1999; Sausen et al., 2005).

To summarize, the linearisation of the climate-chemistry model E39/C with respect to atmospheric emissions is applicable to subsonic air traffic and reproduces the radiative forcing values from various climate agents within $15 \%$, with the exception of water vapour. It is anticipated that AirClim might not be applicable to perturbation scenarios of subsonic air traffic, since the vertical resolution of AirClim is low at subsonic cruise levels.

\section{Climate impact of air traffic}

In this section a first application of AirClim is performed. We investigate the sensitivity of regional emissions on global mean near surface temperature changes and climate impact of subsonic and supersonic air traffic. We are focusing on the importance of $\mathrm{CO}_{2}$ versus $\mathrm{NO}_{\mathrm{x}}$ emissions for subsonic air traffic, a climate impact minimization for options of supersonics and the difference between sub- and supersonic transport with respect to climate change. The numerical efficiency of the linearised model facilitates the analysis of a number of air traffic scenarios, which would not be possible applying complex climate-chemistry models.

Although AirClim has been designed, as a first step, to be applicable to supersonic transport, it basically can be applied to all kind of 3-D emission data. However, the coarse vertical resolution in the area of subsonic transport limits its applicability (see Sect. 4.2). In future, we will enhance this resolution in order to achieve a full applicability with respect to air traffic.

In our study, we concentrate on the TRADEOFF aircraft emission data (Sausen et al., 2005) for the year 2000 and the SCENIC emission data (Rogers et al., 2008 ${ }^{1}$ ) for the years 2025 and 2050 (Table 4) with respect to global and annual mean emissions. For the period prior to 2000 we take historical records into account (IPCC, 1999). The 3-D structure is taken into account for the timeslice 2050, which is important for the intercomparison of different technology options.

\subsection{Climate sensitivity of regional emissions}

In order to intercompare the climate impact of a unit emission in the emission regions, i.e. the regional dependency of the near surface temperature change to the emission region for the year 2100, we have applied AirClim for the pre-defined emission regions (Fig. 2; Table 3) with a normalised emission strength. This comprises a continuation of the results presented in Sect. 3. In Sect. 3 we discussed the input data to AirClim, whereas here these input data are converted into a near surface temperature changes which include assumptions on the temporal evolution of air traffic and the climate sensitivity of climate agents.

It represents the derivative of the near surface temperature with respect to the emission strength $e$ multiplied with a normalised emission $E$. Since the global mean near surface temperature, as calculated by AirClim, is only dependent on the location of the emission $x_{e}$ and the strength of the emission $e$, the results can be interpreted as $\frac{\partial \Delta T\left(x_{e}, e\right)}{\partial e} \times E$. Therefore the strength of the emission $E$ is secondary for the analysis of impact of the emission regions on the temperature response. However, the ratio of water vapour emissions, i.e. fuel consumption, to $\mathrm{NO}_{\mathrm{x}}$ emissions (i.e. $\mathrm{EINO}_{\mathrm{x}}$ ) is important since it defines the ratio between the individual forcings. Here we take the mean value from the SCENIC subsonic emission data $\left(\mathrm{S} 4 ; \mathrm{EI}\left(\mathrm{NO}_{\mathrm{x}}\right)=10.85 \mathrm{~g}\left(\mathrm{NO}_{2}\right) / \mathrm{kg}(\right.$ fuel $)$ ). That means that at each of the 24 grid points of AirClim the total SCENIC emissions are included. Figure 8 shows the global mean near surface temperature change for 2100 as a function of altitude and latitude of the emission (note that we assume constant emissions for the period 2050 to 2100). The temperature increase due to water vapour changes and the temperature decrease due to methane changes (Fig. 8a, c) reflect directly their lifetime pattern (Fig. 6a). The temperature changes due to water vapour and ozone $(8 \mathrm{a}, \mathrm{b})$ also reflect their radiative forcing (Fig. 6c, d). Strongest temperature changes from ozone are found for emissions in the upper tropical troposphere with $80 \mathrm{mK}$ for $1 \mathrm{TgN}$ emitted per year, whereas strongest temperature changes from methane are found in the middle tropical troposphere $(-30 \mathrm{mK}$ per $1 \mathrm{TgN} / \mathrm{year}$ ). Although the lifetime of methane changes is considerably larger than for ozone it does not compensate for the smaller radiative forcing. Hence ozone changes from $\mathrm{NO}_{\mathrm{x}}$ emissions dominate the temperature change over the compensating methane effect (Fig. 8d), at least for this specific emission index of $\mathrm{NO}_{\mathrm{x}}$, or smaller indices. Figure 8e shows the sum of all effects. Clearly, the global mean temperature increases with the height of the emission. There is also a clear difference between tropical and extra-tropical emission locations, with a lower climate impact for emissions at high latitudes.

\subsection{Subsonic air traffic: TRADEOFF and SCENIC}

Figure 9 presents the temporal evolution of temperature changes derived with AirClim for an emission scenario based on historical (IPCC, 1999), present (TRADEOFF), and future (SCENIC, S4) scenarios. Note that again the emissions are kept constant after the year 2050 for illustration purpose. For short-term perturbations (ozone, contrails and water vapour) the temperature change reaches equilibrium in less than 100 years after the emissions are kept constant. 

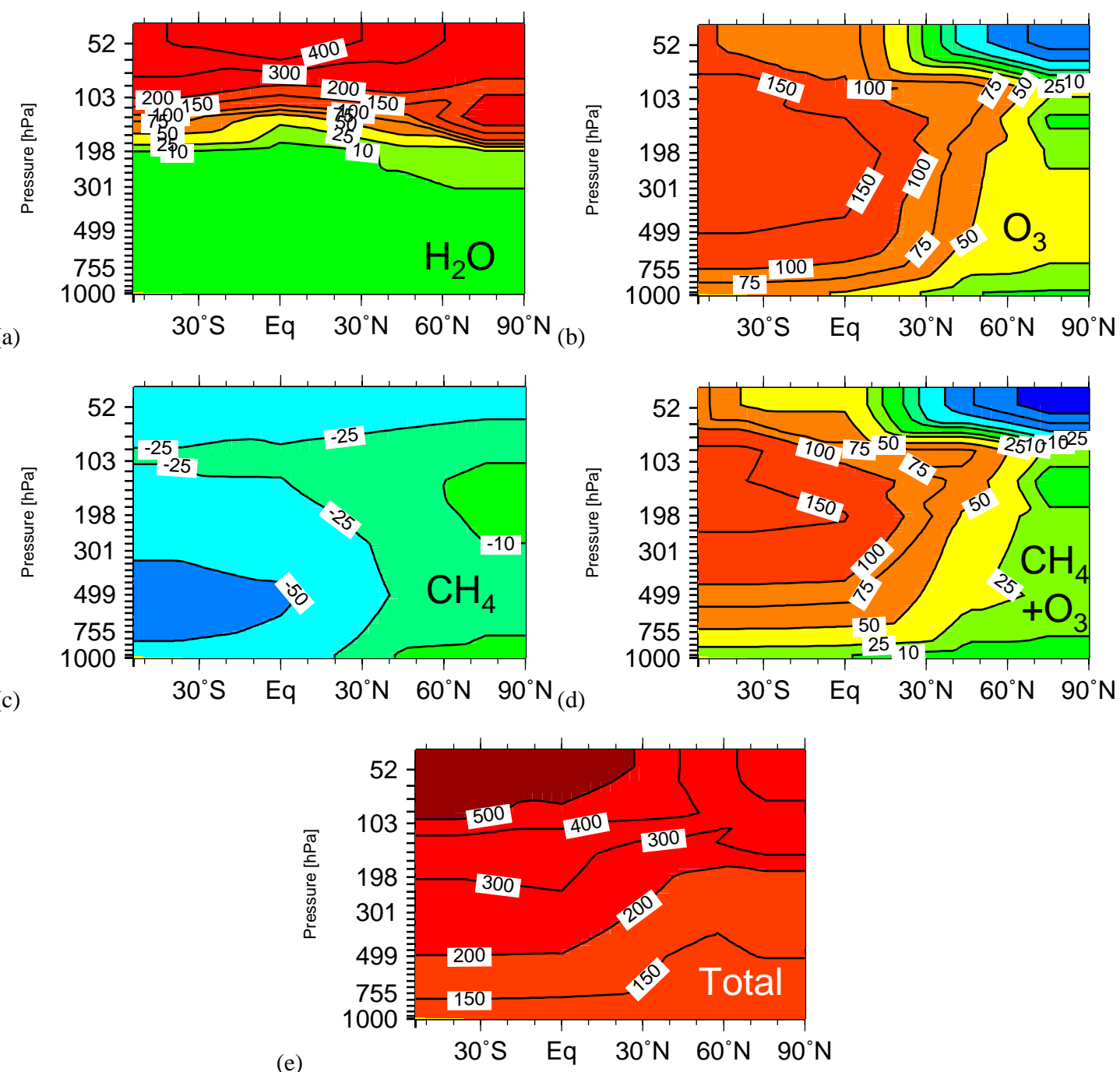

Fig. 8. Global mean near surface temperature changes $[\mathrm{mK}]$ in 2100 as a function of latitude and altitude of the emissions for (a) $\mathrm{H}_{2} \mathrm{O}$ (b) $\mathrm{O}_{3}$ (c) $\mathrm{CH}_{4}$ (d) $\mathrm{O}_{3}+\mathrm{CH}_{4}$ (e) Total. The emissions are normalised to the totals of scenario S4, i.e. subsonic air traffic for 2050.

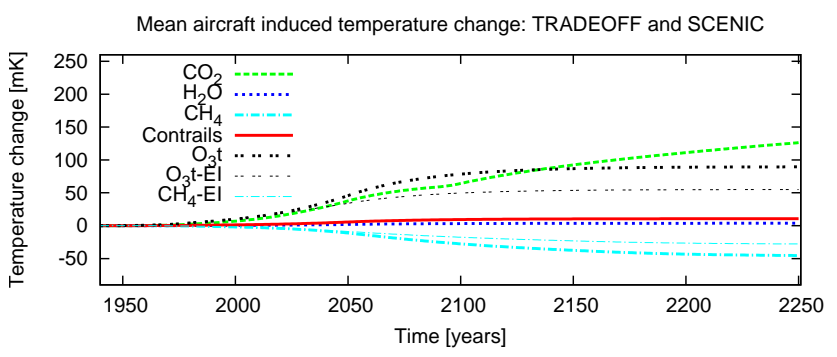

Fig. 9. Temporal development of temperature changes $[\mathrm{mK}]$ due to subsonic aircraft emissions calculated with AirClim. We applied historical data until early 90s (IPCC, 1999), TRADEOFF emissions for 2000 and SCENIC emissions for 2025 and 2050 and constant emissions afterwards. The extension EI indicates a scenario with a reduction of the emission index of $\mathrm{NO}_{\mathrm{x}}$ by $40 \%$.
In Fig. 10 we compare the climate impact of $\mathrm{CO}_{2}$ and $\mathrm{NO}_{\mathrm{x}}$ emissions of subsonic air traffic for the year 2000, 2100, and 2250 applying the metrics radiative forcing (a) and near surface temperature change (b). Note that the year 2250 is only taken into account to represent steady-state for non- $\mathrm{CO}_{2}$ greenhouse gases.

For all points of time, radiative forcing from $\mathrm{CO}_{2}$ is larger than the radiative forcing of the products of $\mathrm{NO}_{\mathrm{x}}$ emissions, i.e. ozone and the sum of ozone and methane (second and third bar compared to first bar at each date). However, ozone and methane induced temperature changes are larger than for $\mathrm{CO}_{2}$ in the year 2000. This difference in the importance of $\mathrm{CO}_{2}$ and $\mathrm{NO}_{\mathrm{x}}$ emissions on radiative forcing and global mean near surface temperature changes is a consequence of the larger efficacy of ozone $(=1.4)$ compared to $\mathrm{CO}_{2}(=1)$ (see Sect. 2.2.5). However, within the uncertainty range (see Sect. 2.4.3) none of both effects exceed the other. In 2100, 

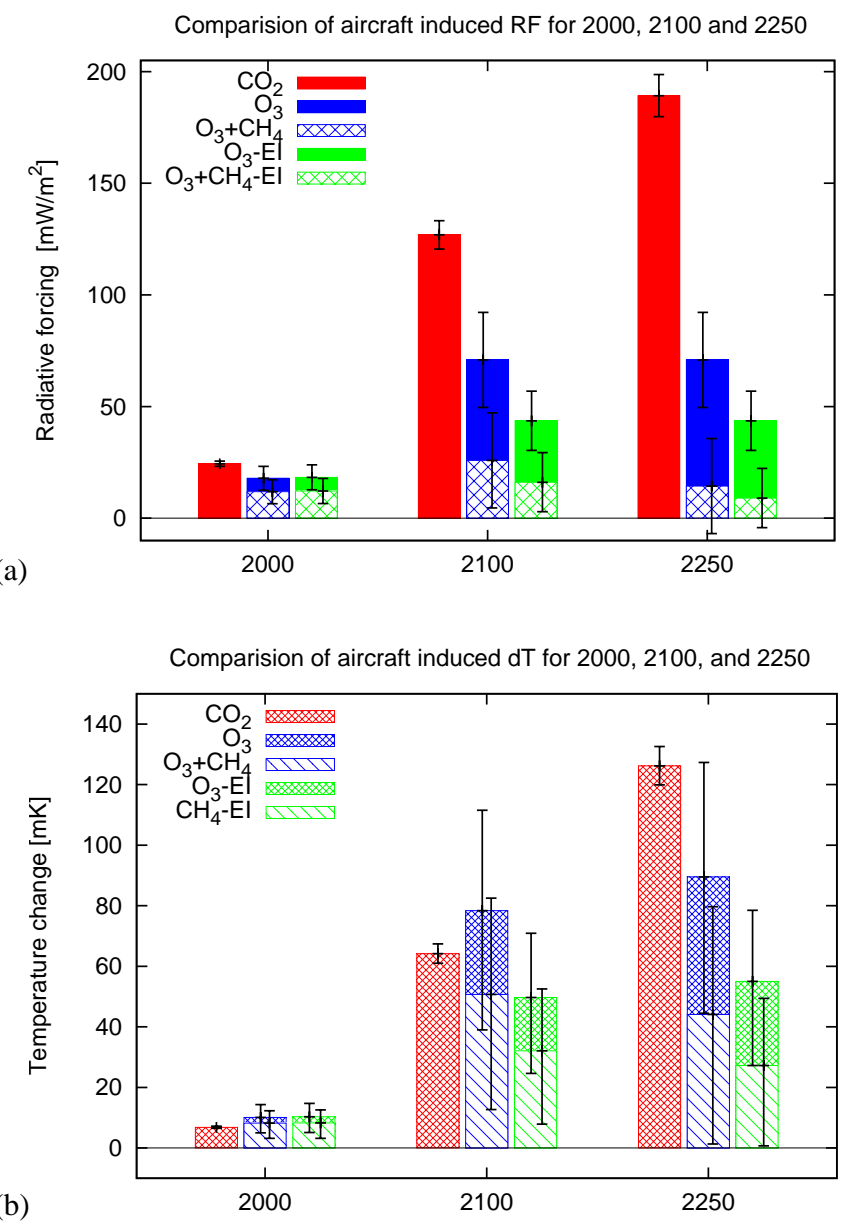

Fig. 10. Intercomparison of the importance of subsonic air traffic $\mathrm{CO}_{2}$ (red) versus $\mathrm{NO}_{\mathrm{x}}$ (blue and green) emissions for climate change with respect to radiative forcing (a) and temperature change (b). The blue and green bars shows the ozone impact from $\mathrm{NO}_{\mathrm{x}}$ emissions (whole bar) and the reduction due to methane (partial bar for $\mathrm{O}_{3}+\mathrm{CH}_{4}$ ). The green bars show results for a sensitivity, a future reduction of the $\mathrm{NO}_{\mathrm{x}}$ emission index by $40 \%$ from 2000 to 2050 .

the temperature change caused by $\mathrm{CO}_{2}$ exceeds that caused by $\mathrm{NO}_{\mathrm{x}}$ emissions (i.e. sum of ozone and methane effect) only in the case of a largely reduced emission index (green boxes). Here we assume a reduction of the $\mathrm{NO}_{\mathrm{x}}$ emission index by $40 \%$ between 2000 and 2050, which will result in an emission index of $6 \mathrm{~g}\left(\mathrm{NO}_{2}\right)$ per $\mathrm{kg}$ fuel as e.g. discussed as an option for future technology (Ponater et al., 2006). This reduction will lower the importance of $\mathrm{NO}_{\mathrm{x}}$ emissions. This illustrates the different temporal evolution of radiative forcing and near surface temperature changes, which indicates the need of a careful use of these metrics. In the year 2250 the climate impact of $\mathrm{CO}_{2}$ emissions dominates over $\mathrm{NO}_{\mathrm{x}}$ emissions.

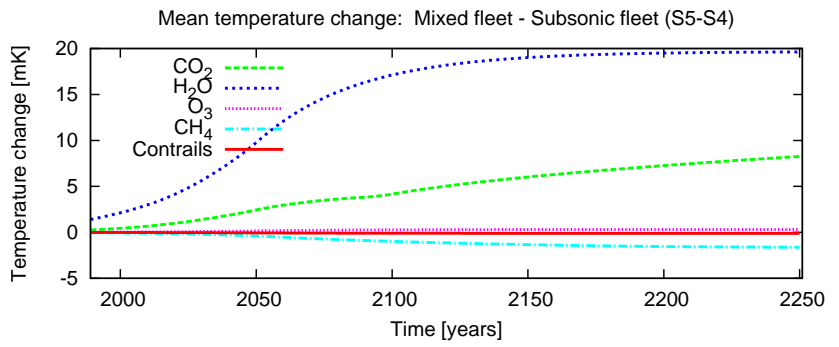

Fig. 11. Temporal development of temperature changes $[\mathrm{mK}]$ due to a partial replacement of subsonic aircraft by supersonics as calculated with AirClim. SCENIC emission scenario S5-S4 is used.

Therefore, although $\mathrm{CO}_{2}$ perturbations have a much larger atmospheric residence time than $\mathrm{NO}_{\mathrm{x}}$, ozone and methane perturbations, the $\mathrm{CO}_{2}$ climate impact in terms of near surface temperature changes is not largely exceeding that of $\mathrm{NO}_{\mathrm{x}}$-emissions in this century.

An interesting question concerns the turn-over point between the $\mathrm{CO}_{2}$ and ozone impact. A simplified approach (see Appendix B) shows that as long as the emissions increase by approximately 6-7\% the radiative forcing from aircraft $\mathrm{CO}_{2}$ and ozone increase with the same rate. This means that the yearly increase in $\mathrm{CO}_{2}$ - $\mathrm{RF}$ due to long-term accumulation effects has the same strength as the increase in ozone RF, which are directly related to the increase in emissions of that year. Note that these values differ if near surface temperature changes are taken into account instead of radiative forcing.

\subsection{Climate impact of a supersonic fleet}

Within the SCENIC project the climate impact of a replacement of 500 subsonic aircraft by supersonics was investigated (Grewe et al., 2007). Four atmosphere-chemistry models were applied in that study (including E39/C) to investigate the climate impact and the impact on ultraviolet radiation for different options of a supersonic fleet.

Here, we find consistency between the results derived with AirClim and the earlier study by Grewe et al. (2007): Fig. 11 shows the temporal evolution of near surface temperature changes for a replacement of 500 subsonic aircraft by supersonics. The same main features as Fig. 9a in Grewe et al. (2007) are found: Water vapour is the main contributor to climate change with regard to a supersonic fleet. Differences occur with respect to ozone since the mean value among the 4 applied atmosphere-chemistry models was negative in Grewe et al. (2007), whereas here we calculate a small positive value. The turn around point between ozone increase at lower levels and ozone depletion at higher altitudes for a specific $\mathrm{NO}_{\mathrm{x}}$ emission is still a major uncertainty (Grewe et al., 2007). Wuebbles et al. (2004) investigated the impact of the emission altitude on ozone column with a two-dimensional model and found a turnaround 


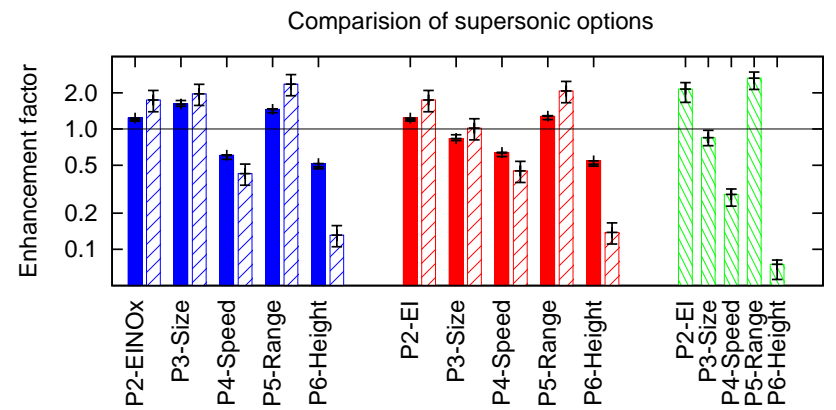

Fig. 12. Relative changes in near surface temperature for the year 2100 (solid bars) and for ozone (dashed bars) with respect to the impact of a supersonic base case scenario (e.g. SCENIC scenario P2 minus S4 divided by S5 minus S4). Changes are given for constant transport volume of the total fleet (blue) and constant supersonic transport volume (red). The product of both factors is added (green) as an overall metric. For each bar an uncertainty range is given, which represents minimum and maximum values. The larger the enhancement factor the larger is the respective impact on climate and ozone. The calculations are performed with AirClim.

point between $13 \mathrm{~km}$ and $15 \mathrm{~km}$, whereas E39/C simulates it around $14.5 \mathrm{~km}$ and $16.5 \mathrm{~km}$. Currently, we are not able to include this uncertainty in AirClim. However, in the future, it could be considered by including multiple input data, precalculated by different models (see Sect. 2.2).

\subsection{Technology options for supersonic aircraft to minimise} climate impact

Within the SCENIC project not only the climate impact of supersonic transport was investigated, but also sensitivities and mitigation options analysed, aiming at reducing the climate impact of such a fleet (Grewe et al., 2007). To each of these options a detailed analysis was performed, which results in detailed emission data sets. These options and sensitivities include a higher $\mathrm{NO}_{\mathrm{x}}$ emission index (P2), a doubling of the fleet size (P3), a decreased speed from Mach 2 to Mach 1.6 (P4), an increased range (P5), and a decreased cruise altitude (P6). Due to computational reasons not all options could be investigated by all models. In fact only one modeling group (University Cambridge) was able to investigate all options with one model. Here we repeat this investigation with AirClim to enlarge the basis for the interpretation.

Since AirClim is numerically efficient, it can be applied to all of the scenarios. Fig. 12 is the analogous figure to Fig. 10 by Grewe et al. (2007) showing the impact of these options as a relative change with respect to the base case mixed fleet scenario (S5). The metrics near surface temperature change (blue filled bars) and ozone depletion (blue dashed bars) are taken into account, as indicators for climate and UV changes. Since the options do not account for the same supersonic transport volume, we additionally normalised the results to

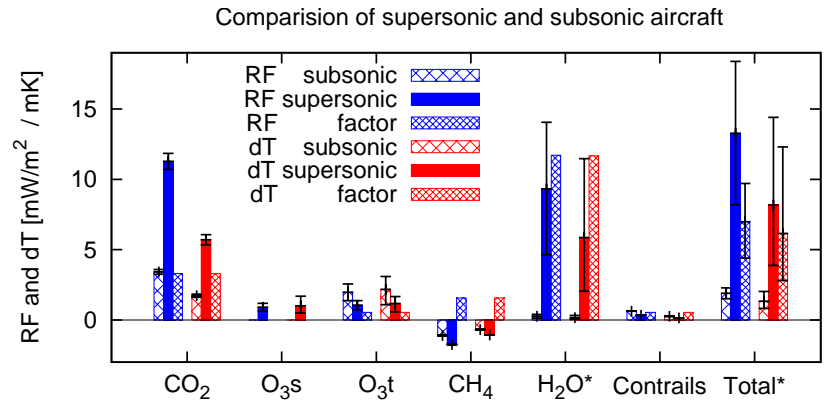

Fig. 13. Intercomparison of the near surface temperature change caused by supersonic (filled) aircraft and the respective (replaced) subsonic aircraft (dashed) for 2100. The third column in each group indicates the factor between the supersonic and subsonic impact. Ozone is split into the stratospheric $\left(\mathrm{O}_{3} \mathrm{~s}\right)$ and tropospheric $\left(\mathrm{O}_{3} \mathrm{t}\right)$ contribution. *Values of RF and temperature changes are divided by 3 for presentability reasons.

the same supersonic transport volume (red bars). The product of the two metrics is than given as an overall metric (green bars).

In principle, the results lead to the same conclusions as in Grewe et al. (2007), i.e. the scenarios P6 (cruise altitude) and P4 (speed) show the smallest environmental impact. Differences occur especially in the calculated temperature change caused by an increased emission index of $\mathrm{NO}_{\mathrm{x}}(\mathrm{P} 2)$ and increased range (P5). This mainly results from the different impact on ozone in AirClim and the mean model in Grewe et al. (see discussion above, Sect. 5.3).

Note, the errorbars express different ranges of uncertainty in Fig. 10 in Grewe et al. (2007) and our Fig. 12. Grewe et al. (2007) include, whenever possible, uncertainties covered by the range of model results, whereas in AirClim this uncertainty cannot be estimated, since only E39/C has been applied to derive the precalculated input data (Sect. 2.2). Differences are still within the range of uncertainty indicated by these errorbars, except for P5 and P6. The temperature increase derived for scenario $\mathrm{P} 5$ and the ozone depletion in scenario P6 significantly differs between the multi-model and AirClim approach. However, P5 and P6 results were only obtained by one model (SLIMCAT, University Cambridge) in Grewe et al. (2007) and are somehow biased towards this model. An uncertainty range for ozone depletion could not be provided in Grewe et al. (2007) for the same reasons. Anyway, the main conclusion indicated by their results is confirmed.

\subsection{Direct intercomparison of sub- and supersonic aircraft}

The SCENIC scenarios discussed above are not suitable for a direct intercomparison of a subsonic and supersonic aircraft, since the impact of the replaced subsonic cannot be evaluated. Therefore an additional scenario (S4core) has been 
calculated which includes only those subsonic aircraft, which are not replaced by supersonics in the mixed fleet scenario (R. Egelhofer, personal communication). Hence the difference between S4 and S4core and the difference between S5 and $\mathrm{S} 4$ core refers to aircraft with the same characteristics and transport volume.

Figure 13 shows the direct intercomparison between those subsonic and supersonic aircraft, i.e. the impact of scenario S4 minus S4core (crossed) and the impact of scenario S5 minus S4core (filled). The results clearly show that the total climate impact (near surface temperature change in 2100) of supersonics is approximately 6 times of that from subsonic aircraft. The approach considers in service of either aircraft in 2015 and a full fleet in 2050 . The change of dates by 10 years has an impact on the factor of around $10 \%$. The results are almost independent of the chosen time horizon (year 2100), it varies by $\pm 5 \%$ between 2050 and 2150 . By taking into account the whole range of uncertainty described in Sect. 2.4.3 the factor varies between 3 and 12. The fuel consumption for the subsonics, which are replaced is around $20 \mathrm{Tg} / \mathrm{year}$ compared to $60 \mathrm{Tg} / \mathrm{year}$ for the supersonics. This well explains the radiative forcing and temperature changes with respect to $\mathrm{CO}_{2}$. The large difference in near surface temperature change arises predominantly from large water vapour changes, which are a consequence of the high emission altitude and the longer atmospheric residence times. Also the large uncertainty range arises from the uncertainties in simulating water vapour effects.

\section{Conclusions}

In this study we have proposed a methodology to assess the climate impact of aircraft technology options. The main climate agents with respect to super- and subsonic air traffic are $\mathrm{CO}_{2}, \mathrm{H}_{2} \mathrm{O}, \mathrm{O}_{3}, \mathrm{CH}_{4}$, and contrails. The functional chain from emissions to climate change of these species is complex and includes transport, chemistry, microphysics, and radiation. We have shown that the linearisation of these processes is possible and can be used within a more simple climate assessment tool, which facilitates the numerical efficient conversion of emission datasets into chosen impact parameter for climate change. Applying detailed climate-chemistry modelling requires large computational resources, i.e. turn around times in the order of weeks to months, whereas AirClim can be run within seconds on a desktop computer.

As a metric, we propose near surface temperature changes in 2100 , however we also consider its temporal evolution. Forster et al. (2006, 2007) gave a list of requirement necessary for metrics evaluating the climate impact of air traffic. They clearly showed that a simple conversion factor between $\mathrm{CO}_{2}$ radiative forcing and other forcings is not suitable and that a metric should be based on emissions. Further, they pointed out that the dependence on the location of the emission, model uncertainties, varying climate efficacies have to be considered thoroughly. We take these requirements into account, since AirClim is designed to take the location of the emissions into account and uncertainty ranges are considered for lifetimes, radiative forcing calculations (which include model uncertainties) and efficacies. They further point out that a suitable time horizon has to be chosen and propose 100 years. For the intercomparison of technology options we compare the impact of the related emissions, which start in 2015 (point of in-service), increase until 2050, and are constant afterwards. We are looking at the temporal development between 2015 and 2100, and in some cases until 2250 (steady-state) in order to be independent of a specific time-horizon. Hence, those requirements are fullfilled with the approach chosen for AirClim. However, for the future it would be desirable to include a suite of metrics in the model AirClim.

In order to linearise a complex climate-chemistry model (here: E39/C) we performed simulations applying a number of idealised emission scenarios. The results of these scenarios give insights into the atmospheric response, in terms of radiative forcing and temperature change to normalised emissions. Water vapour emissions show an increasing climate impact the higher or the closer to the tropics the emissions occur. $\mathrm{NO}_{\mathrm{x}}$ has the largest impact on global mean temperatures via ozone formation, when emitted at tropical latitudes around 100 to $200 \mathrm{hPa}$. Methane reduction caused by $\mathrm{NO}_{\mathrm{x}}$ emissions is included in AirClim. Although methane tends to reduce the warming and although atmospheric residence times are larger than those for ozone the overall effect of $\mathrm{NO}_{\mathrm{x}}$ emissions is still one of a warming. The $\mathrm{NO}_{\mathrm{x}}$ effect is reversed at high supersonic cruise levels, where $\mathrm{NO}_{\mathrm{x}}$ leads to ozone depletion.

Stevenson et al. (2004) suggested that the integrated ozone radiative forcing could be outweighed by the methane impact when regarding short-term pulse emissions. In our study we find a significant reduction by approximately $35 \%$ of the near surface temperature response in 2100 . However with a large range of uncertainty between $20 \%$ to $70 \%$.

The differences are to some extend arising from the larger ozone climate sensitivity, which is not taken into account in Stevenson et al. (2004), since they concentrated on radiative forcing, whereas we were focusing on near surface temperature changes. In terms of radiative forcing a reduction of $35 \%$ (25\% to 50\%) and 65\% (50\% to $90 \%$ ) is found for 2000 and 2100 , respectively. However it has to be noted that we are not taking into account ozone changes resulting from methane perturbations on time-scales exceeding 5 years, i.e. they are represented in the steady state simulations, but not explicitely treated in the linearisation approach. A separation of longterm and short-term effects in the steady-state simulations is planned for the future.

Similar approaches to calculate the temperature changes caused by air traffic emissions have been used previously (Sausen and Schumann, 2000; Ponater et al., 2006; Ling et al., 2006; Lukachko et al., 2006; Grewe et al., 2007; Marais 
et al., 2008). They are all based on the same relationship between radiative forcing and temperature. Here we revised those methods with two main characteristics. First, the calculation of the radiative forcing for a specific emission dataset is included in the AirClim model by linearising these processes instead of precalculating them with detailed climatechemistry models. Hence the location of the emission as well as its strength plays a key role in the determination of the radiative forcing. Second, we introduced typical residence times for stratospheric and tropospheric perturbations and for methane. With this, each regarded species has a typical residence time, which is perturbed by the air traffic emissions. Hence, the temporal development of ozone and methane perturbations differ remarkably in contrast to earlier studies.

The results performed for a subsonic fleet (TRADEOFF for 2000, SCENIC for 2050) show good agreement with previously calculated values for radiative forcing (Sausen et al., 2005). The calculated temperature change clearly shows that in future, e.g. $2100, \mathrm{CO}_{2}$ and $\mathrm{NO}_{\mathrm{x}}$ emissions are equally important under the assumption of a constant fleet after 2050 . This assumptions is likely to be unrealistic, but illustrates the response to a sustained emission. Assuming a further increase would even increase the importance of ozone compared to $\mathrm{CO}_{2}$, because the short-term effects from the increase in ozone due to an increase in air traffic and emissions dominate over long-term effects resulting from increasing $\mathrm{CO}_{2}$ concentrations due to its long adjustment time for perturbations. This applies as long as air traffic increases considerably, i.e. in the range of 6 to $7 \%$, if the $\operatorname{EI}\left(\mathrm{NO}_{\mathrm{x}}\right)$ remains unchanged. That implies that all future measures for climate stabilisation should not only concentrate on $\mathrm{CO}_{2}$, but also on $\mathrm{NO}_{\mathrm{x}}$ emissions and of course all other effects like contrails, which will become more important if the effect of a transition into cirrus will be included.

By means of an extension to the SCENIC database (courtesy of R. Egelhofer) we were able to directly compare subsonic and supersonic aircraft, in the sense that transport volume is the same and the aircraft themselves are comparable. Such a comparison has not been performed so far (IPCC, 1999; Grewe et al., 2007). Instead, the impacts of a whole mixed fleet have been compared to a whole subsonic fleet. Our results show that supersonic aircraft of this size (250 passenger, $5400 \mathrm{~nm}$ range) have a six times larger climate impact than their subsonic counterpart. Taking a number of uncertainties in the lifetimes of the perturbations, radiative forcing calculation and efficacies into account a range between 3 and 12 is estimated. Smaller supersonic jets, i.e. business jets (e.g. 8 passenger $3500 \mathrm{~nm}$ ) are also likely to have a larger climate impact than their subsonic counterparts. However, the enhancement is probably less than for larger aircraft, since one of the driving parameters for the enhancement of climate impact is the cruise altitude difference between subsonic and supersonic aircraft. Subsonic business jets already tend to fly at a higher altitudes than regular passenger aircraft to prevent a disturbance of air traffic. Therefore the differences in cruise altitude between sub- and supersonic business jets are expected to be smaller than for passenger aircraft.

\section{Appendix A}

\section{Simulation of methane changes}

For the simulation of methane changes, the change in methane lifetime $(\delta)$ is estimated based on the input data (see Sect. 2.2). This represents an enhanced methane loss, which would become totally effective after a time span exceeding its lifetime. Earlier studies (e.g. Sausen et al. (2005)), however, assumed steady-state between methane loss rate and methane concentration changes. Here we assume that the relation between loss rates and concentration can be expressed by a linear differential equation:

$\frac{d}{d t} \mathrm{C}^{\mathrm{CH}_{4}}=\operatorname{Prod}(t)-\tau_{\mathrm{CH}_{4}}^{-1} \times \mathrm{C}^{\mathrm{CH}_{4}}$

Changes in the lifetime will then result in

$$
\frac{d}{d t} \tilde{\mathrm{C}}^{\mathrm{CH}_{4}}=\operatorname{Prod}(t)-\tau_{\mathrm{CH}_{4}}^{-1} \times(1+\delta(t))^{-1} \times \tilde{\mathrm{C}}^{\mathrm{CH}_{4}} .
$$

The linear differential Eq. (3) is then derived by the difference in Eqs. (A2) and (A1), $\Delta C^{\mathrm{CH}_{4}}=\tilde{C}^{\mathrm{CH}_{4}}-C^{\mathrm{CH}_{4}}$. Note, that not methane production rates, i.e. methane emissions, have to be known explicitely, but the background methane concentration.

\section{Appendix B}

\section{Turn-over between $\mathrm{CO}_{2}$ and ozone $\mathrm{RF}$}

The lifetime of a $\mathrm{CO}_{2}$ and an ozone perturbation differs considerably. Hence the temporal evolution of these perturbations and the associated RF is determined by their lifetimes and the changes in emissions. If we focus on a relatively short time period, e.g., between 2000 and 2030, we can approximate the $\mathrm{CO}_{2}$ lifetime as infinitive and ozone to be in steady state with a certain lifetime (e.g. 22 days; Stevenson et al. (2006)). For that 30 year period ozone and $\mathrm{CO}_{2}$ perturbations can then be approximated by simple differential equations

$$
\begin{aligned}
\frac{d}{d t} \Delta \mathrm{C}^{\mathrm{CO}_{2}} & =\mathrm{E}^{\mathrm{CO}_{2}}=\mathrm{EI}_{\mathrm{CO}_{2}} \times \mathrm{FC} \\
\Delta \mathrm{C}^{\mathrm{O}_{3}} & =\mathrm{E}^{\mathrm{CO}_{2}} \times \mathrm{EI}_{O_{3}} \times \tau_{\mathrm{O}_{3}},
\end{aligned}
$$

where $\mathrm{EI}_{\mathrm{O}_{3}}$ gives the chemical response to an emission, i.e. includes the $\mathrm{EI}_{\mathrm{NO}_{\mathrm{x}}}$ and the related ozone change, $\mathrm{FC}$ 
the fuel consumption. The question is, under which conditions are the changes in $\mathrm{CO}_{2}$ and ozone radiative forcings equal? With $r \mathrm{CO}_{2}$ and $r^{\mathrm{O}_{3}}$ conversion factors from concentration changes to RF, we obtain:

$$
\begin{aligned}
& \frac{d}{d t} \mathrm{RF}^{\mathrm{CO}_{2}}=\frac{d}{d t} \mathrm{RF}^{\mathrm{O}_{3}} \\
& \frac{d}{d t} r^{\mathrm{CO}_{2}} \times \mathrm{EI}_{\mathrm{CO}_{2}} \times \Delta C^{\mathrm{CO}_{2}}=r^{\mathrm{O}_{3}} \times \mathrm{EI}_{\mathrm{O}_{3}} \times \Delta C_{\mathrm{O}_{3}} \\
& r^{\mathrm{CO}_{2}} \times \mathrm{EI}_{\mathrm{CO}_{2}} \times \mathrm{FC}=r^{\mathrm{O}_{3}} \times \mathrm{EI}_{\mathrm{O}_{3}} \times \tau_{\mathrm{O}_{3}} \times \frac{d}{d t} \mathrm{FC} .
\end{aligned}
$$

Hence we can formulate a condition for the relative increase in fuel consumption:

$$
\begin{aligned}
\frac{\frac{d}{d t} \mathrm{FC}}{\mathrm{FC}} & =\frac{\mathrm{FC} \times \mathrm{EI}_{\mathrm{CO}_{2}} \times r \mathrm{CO}_{2}}{\mathrm{FC} \times \mathrm{EI}_{O_{3}} \times \tau_{\mathrm{O}_{3}} \times r^{\mathrm{O}_{3}}} \\
& =\frac{\mathrm{RF}_{\mathrm{Pulse}_{2}}^{\mathrm{CO}}}{\mathrm{RFO}_{3}} \\
& =\frac{1.5 \mathrm{~mW} / \mathrm{m}^{2}}{21.9 \mathrm{~mW} / \mathrm{m}^{2}}=6.7 \%,
\end{aligned}
$$

where $1.73 \times 10^{11} \mathrm{~kg} / \mathrm{a}$ fuel consumption for 2000 is used, which gives an emission of $5.45 \times 10^{11} \mathrm{~kg} / \mathrm{a} \mathrm{CO} 2$. This relates to an increase of $0.103 \mathrm{ppmv}$ and a radiative forcing of $1.5 \frac{\mathrm{mW}}{\mathrm{m}^{2}}$.

Therefore, the aircraft induced $\mathrm{CO}_{2}$ and ozone radiative forcings increase by the same rate as long as fuel consumption increases by around 6 to $7 \%$ per year. This increase rate represents the ratio between the radiative forcing of a one year $\mathrm{CO}_{2}$ pulse emission and the ozone radiative forcing.

Acknowledgements. This study has been partly supported by the European Commission through the Integrated Project HISAC (development and verification of AirClim), the Network of Excellence ECATS (direct intercomparison of sub- and supersonic transport) and QUANTIFY (estimate of methane changes based on loss rates) under the 6th Framework Programme. Many thanks to R. Egelhofer, Technical University Munich and C. Marizy, Airbus for providing additional and more detailed datasets of the SCENIC database and K. Gierens and C. Fichter, DLR for internal review. Thanks also to Keith Shine, University Reading and 2 anonymous reviewer for their helpful comments.

Edited by: W. Collins

\section{References}

Dameris, M., Grewe, V., Ponater, M., Deckert, R., Eyring, V., Mager, F., Matthes, S., Schnadt, C., Stenke, A., Steil, B., Brühl, C., and Giorgetta, M.: Long-term changes and variability in a transient simulation with a chemistry-climate model employing realistic forcing, Atmos. Chem. Phys., 5, 2121-2145, 2005.
Forster, P.M. de F., Shine, K.P., Stuber, N.: It is premature to include non- $\mathrm{CO}_{2}$ effects of aviation in emission trading schemes, Atmos. Environ., 40, 1117-1121, 2006.

Forster, P.M. de F., Shine, K.P., Stuber, N.: Corrigendum to Ït is premature to include non- $\mathrm{CO}_{2}$ effects of aviation in emission trading schemes; Atmos. Environ., 41, 3941, 2007.

Fuglestvedt, J.S., Berntsen, T.K., Isaksen, I.S.A., Mao, H., Liang, X.-Z., Wang, W.-C.: Climatic forcing of nitrogen oxides through changes in tropospheric ozone and methane: global 3D model studies, Atmos. Environ., 33, 961-977, 1999.

Fuglestvedt, J., Berntsen, T., Godal, O., Sausen, R., Shine, K., and Skodvin, T.: Metrics of climate change: Assessing radiative forcing and emission indices, Clim. Change, 58, 267-331, 2003.

Fuglestvedt, J., Berntsen, T., Myhre, G., Rypdal, K., and Skeie, R.: Climate forcing from the Transport Sectors, PNAS, 105, 454458, doi:10.1073/pnas.0702958104, 2008.

Grewe, V., Dameris, M., Fichter, C., Sausen, R.: Impact of aircraft $\mathrm{NO}_{\mathrm{x}}$ emissions. Part 1: interactively coupled climatechemistry simulations and sensitivities to climate-chemistry feedback, lightning and model resolution, Meteorol. Z., 3, 177186, 2002.

Grewe, V.: The origin of ozone, Atmos. Chem. Phys., 6, 14951511, 2006.

Grewe, V., Stenke, A., Ponater, M., Sausen, R., Pitari, G., Iachetti, D., Rogers, H., Dessens, O., Pyle, J., Isaksen, I., Gulstad, L., Sövde, O.A., Marizy, C., and Pascuillo, E.: Climate impact of supersonic air traffic: an approach to optimize a potential future supersonic fleet - Results from the EU-project SCENIC, Atmos. Chem. Phys., 7, 5129-5145, 2007.

Hansen, J., Sato, M., Ruedy, R., Nazarenko, L., Lacis, A., Schmidt, G., Russell, G., Aleinov, I., Bauer, M., Bauer, S., Bell, N., Cairns, B., Canuto, V., Chandler, M., Cheng, Y., DelGenio, A., Faluvegi, G., Fleming, E., Friend, A., Hall, T., Jackman, C., Kelley, M., Kiang, N., Koch, D., Lean, J., Lerner, J., Lo, K., Menon, S., Miller, R., Minnis, O., Novakov, T., Oinas, V., Perlwitz, J., Perlwitz, J., Rind, D., Romanou, A., Shindell, D., Stone, P., Sun, S., Tausnev, N., Tresher, D., Wielicki, B., Wong, T., and Zhang, S.: Efficacy of climate forcings, J. Geophys. Res., 110, D18104, doi:10.1029/2005JD005776, 2005.

Hein, R., Dameris, M., Schnadt, C., Land, C., Grewe, V., Köhler, I., Ponater, M., Sausen, R., Steil, B., Landgraf, J., and Brühl, C.: Results of an interactively coupled atmospheric chemistry-general circulation model: Comparison with observations, Ann. Geophys., 19, 435-457, 2001.

IPCC: Special report on aviation and the global atmosphere, in: Intergovernmental Panel on Climate Change, edited by: Penner, J. E., Lister, D. H., Griggs, D. J., Dokken, D. J., McFarland, M., Cambridge University Press, New York, NY, USA, 1999.

IPCC: Climate Change 2001 - The scientific basis. Contributions of working group I to the Third Assessment Report of the Intergovernmental Panel of Climate Change (IPCC), Intergovernmental Panel on Climate Change, Cambridge University Press, New York, NY, USA, 2001.

IPCC: Climate Change 2007 - The physical science basis. Working group I. Contributions to the Fourth Assessment Report of the Intergovernmental Panel of Climate Change (IPCC), Intergovernmental Panel on Climate Change, Cambridge University Press, New York, NY, USA, 2007.

Isaksen ISA, Zerefos C, Kourtidis K, Meleti C, Dalsøren SB, Sun- 
det JK: Tropospheric ozone changes at unpolluted and semipolluted regions induced by stratospheric ozone changes, J. Geophys. Res., 110:D02302. doi:10.1029/2004JD004618, 2005.

Joshi, M., Shine, K., Ponater, M., Stuber, N., Sausen, R., and Li, L.: A comparison of climate response to different radiative forcings in three general circulation models: towards an improved metric of climate change, Clim. Dyn., 20, 843-854, 2003.

Land, C., Ponater, M., Sausen, R., and Roeckner, E.: The ECHAM4.L39(DLR) atmosphere GCM, Technical description and climatology, DLR-Forschungsbericht, 1991-31, 45 pp., ISSN 1434-8454, Deutsches Zentrum für Luft- und Raumfahrt, Köln, Germany, 1999.

Ling, L., Lee, D., and Sausen, R.: A climate response model for calculating aviation effects, IN: Book of abstracts, International Conference on Transport, Atmosphere and Climate 26-29 June 2006, Oxford, UK, http://www.pa.op.dlr.de/tac, 23, 2006.

Lukachko, S., Waitz, I., and Marais, M.: Valuing the Impact of Aviation on Climate, IN: Book of abstracts, International Conference on Transport, Atmosphere and Climate 26-29 June 2006, Oxford, UK, http://www.pa.op.dlr.de/tac, 24, 2006.

Manabe, S. and Strickler, R.: Thermal equilibrium of the atmosphere with a convective adjustment, J. Atmos. Sci., 21, 361385, 1964.

Marais, K., Lukachko, S.P., Jun, M., Mahashabde, A., Waitz, I.A.: Assessing the impact of aviation on climate, Meteorol. Z., 17, 157-172, 2008.

Marquart, S., Ponater, M., Mager, F., Sausen, R.: Future development of contrail cover, optical depth, and radiative forcing: Impacts of increasing air traffic and climate change, J. Clim., 16, 2890-2804, 2003.

Ponater, M., Marquart, S., and Sausen, R.: Contrails in a comprehensive global climate model: Parameterisation and radiative forcing results, J. Geophys. Res., 107, 4164, doi:10.1029/2001JD000429, 2002.

Ponater, M., Marquart, S., Sausen, R., and Schumann, U.: On contrail climate sensitivity, Geophys. Res. Lett., 32, L10706, doi:10.1029/2005GL022580, 2005.

Ponater, M., Pechtl, S., Sausen, R., Schumann, U., and Hüttig, G.: Potential of the cryoplane technology to reduce aircraft climate impact: A state-of-the-art assessment, Atmospheric Environment, 40, 6928-6944, doi:10.1016/j.atmosenv.2006.06.036, 2006.

Reithmeier, C. and Sausen, R.: ATTILA - Atmospheric Tracer Transport in a Lagrangian Model, Tellus B, Chem. Phys. Meteorol., 54, 278-299, 2002.

Sausen, R. and Schumann, U.: Estimates of the climate response to aircraft $\mathrm{CO}_{2}$ and $\mathrm{NO}_{\mathrm{x}}$ emissions scenarios, Clim. Change, 44, 25-58, 2000.

Sausen, R., Gierens, K., Ponater, M., and Schumann, U.: A diagnostic study of the global distribution of contrails, Part I: present day climate, Theor. Appl. Climatol., 61, 127-141, 1998.
Sausen, R., Isaksen, I., Grewe, V., Hauglustaine, D., Lee, D. S., Myhre, G., Köhler, M. O., Pitari, G., Schumann, U., Stordal, F., and Zerefos, C.: Aviation Radiative Forcing in 2000: An Update on IPCC (1999), Meteorol. Z., 14, 555-561, 2005.

Schumann, U., Busen, R., and Plohr, M.: Experimental test of the influence of propulsion efficiency on contrail formation, J. Aircraft, 37, 1083-1087, 2000.

Shine, K., Berntsen, T., Fuglestvedt, J., and Sausen, R.: Scientific issues in the design of metrics for inclusion of oxides of nitrogen in global climate agreements, PNAS, 44, 15 768-15 773, 2005.

Shine, K.P., Fuglestvedt, J.S., Kinfe, H., and Stuber, N.: Alternatives to the global warming potential for comparing climate impacts of emissions of greenhouse gases, Clim. Change, 68, 281302, 2005.

Steil, B., Dameris, M., Brühl, C., Crutzen, P., Grewe, V., Ponater, M., and Sausen, R.: Development of a Chemistry Module for GCMs: First Results of a Multiannual Integration, Ann. Geophys., 16, 205-228, 1998.

Stenke, A., Grewe, V., and Pechtl, S.: Do supersonic aircraft avoid contrails?, Atmos. Chem. Phys., 8, 955-967, 2008a.

Stenke, A., Grewe, V., and Ponater, M.: Lagrangian transport of water vapor and cloud water in the ECHAM4 GCM and its impact on the cold bias, Clim. Dynam., doi:10.1007/s00382-007-03475 , in press, $2008 \mathrm{~b}$.

Stevenson, D., Doherty, R., Sanderson, M., Collins, W., Johnson, C., and Derwent, R.: Radiative forcing from aircraft $\mathrm{NO}_{\mathrm{x}}$ emissions: Mechanisms and seasonal dependence, J. Geophys. Res, 109, D17307, doi:10.1029/2004JD004759, 2004.

Stevenson, D. S., Dentener, F. J., Schultz, M. G., Ellingsen, K., van Noije, T. P. C., Wild, O., Zeng. G., et al.: Multimodel ensemble simulations of present-day and near-future tropospheric ozone, J. Geophys. Res., 111, D08301, doi:10.1029/2005JD006338, 2006.

Stuber, N., Sausen, R., and Ponater, M.: Stratosphere adjusted radiative forcing calculations in a comprehensive climate model, Theor. Appl. Climatol., 68, 125-135, 2001.

Taalas, P., Damski, J., Kyrö, E., Ginzburg, M., and Talamoni, G.: Effect of stratospheric ozone variations on UV radiation and on tropospheric ozone at high latitudes, J. Geophys. Res., 102(D1), 1533-1540, doi:10.1029/96JD02310, 1997.

Wit, R. C. N., Boon, B. H., van Velzen, A., Cames, M., Deuber, O., and Lee, D. S.: Giving wings to emission trading - Inclusion of aviation under the European Emission Trading System (ETS): Design and impacts, CE-Delft, 05.7789.20, Netherlands, 2005.

Wuebbles, D., Dutta, M., Patten, K., and Baughcum, S.: Parametric study of potential effects of aircraft emissions on stratospheric ozone, in: Proceedings of the AAC-Conference, July 2003, Friedrichshafen, Germany, edited by: Sausen, R., Fichter, C., and Amanatidis, G., 140-144, 2004. 